\title{
Use of potassium chloride and flavor enhancers in low sodium Cheddar cheese
}

\author{
J. Grummer, N. Bobowski, M. Karalus, Z. Vickers, and T. Schoenfuss ${ }^{1}$ \\ Department of Food Science and Nutrition, University of Minnesota, St. Paul 55108
}

\begin{abstract}
We investigated use of potassium chloride $(\mathrm{KCl})$ to maintain both the salty flavor and to replace the preservative effects of salt when reducing the sodium content in natural cheese. Because salt replacers can affect flavor because of inherent off-flavors, such as bitter and metallic, we examined the use of flavor enhancers for their ability to modulate some of these undesirable sensory effects. Stirred-curd Cheddar-style cheese was manufactured using 2 cheese-making procedures (different curd knife sizes and target salting titratable acidities), in duplicate. Curd was salted with sodium chloride $(\mathrm{NaCl})$ or $60 \%$ reduced sodium blends of $\mathrm{NaCl}$ and $\mathrm{KCl}$ (2 different sources). Curd was also salted at a $60 \%$ reduced sodium rate with $\mathrm{NaCl}$ and $\mathrm{KCl}$ with added flavor enhancers. A hydrolyzed vegetable protein/yeast extract blend, a natural "potassium-blocking type" flavor, disodium inosinate, or disodium guanylate were each blended with the reduced sodium salt blend and added to curd at the salting step. The resulting blocks of cheese were aged for 5 mo and evaluated monthly for chemical, microbial, and sensory differences. At 5 mo of aging, we measured liking for the cheeses using a consumer panel. Overall, cheeses were well liked by the consumer panel, and the scores of reduced sodium cheese with 2 different $\mathrm{KCl}$ sources were not different from those of the full-sodium control. The addition of flavor enhancers to Cheddar curd had mixed results, with one improving the consumer flavor liking only slightly over $\mathrm{KCl}$, and one (disodium inosinate) significantly reducing consumer flavor liking scores, presumably due to the amount of umami flavor it contributed. Potassium chloride replacement salts sourced from different manufacturers affected the chemical and flavor properties of cheese, and changes to $\mathrm{pH}$ and temperature targets may be necessary to yield cheese with the moisture and $\mathrm{pH}$ targets desired. The cheese-making procedure used also influenced fla-
\end{abstract}

Received August 13, 2012.

Accepted November 29, 2012.

${ }^{1}$ Corresponding author: tschoenf@umn.edu vors observed, which resulted in higher levels of brothy flavor in cheese made with smaller curd knives and a higher target salting titratable acidity. This effect resulted in lower consumer liking scores.

Key words: sodium reduction, cheese, water activity, $\mathrm{KCl}$, salt replacer

\section{INTRODUCTION}

Sodium content in processed foods is considered to be a public health concern because of its potential to contribute to the development of hypertension in some individuals, which can be a precursor to conditions such as cardiovascular disease (Doyle and Glass, 2010; Cotugna and Wolpert, 2011; Appel et al., 2012). Cheddar cheese contains approximately 615 to $620 \mathrm{mg}$ of sodium/100 g of cheese (Agarwal et al., 2011; USDA, 2011); therefor, one serving provides approximately $8 \%$ of the Food and Drug Administration's daily reference value (FDA, 2009). Cheddar cheese is also an ingredient in process cheese and in sauces, so effective techniques to reduce the sodium content could have significant health benefits.

Salt $(\mathrm{NaCl})$, and its ratio to moisture content, is very important in natural cheese as it affects flavor, the activity of microbial cultures and non-starter microorganisms, and affects moisture removal during cheese manufacturing (Guinee, 2004; Upreti and Metzger, 2007). Mineral salt replacers can be added to maintain the enzymatic and microbial stability by maintaining the water activity $\left(\mathbf{a}_{\mathrm{w}}\right)$ of the cheese to that of full-sodium.

In a previous study, we investigated the effect of different mineral salt replacers in reduced sodium, stirredcurd Cheddar-style cheese at concentrations that maintained the same $\mathrm{a}_{\mathrm{w}}$ as full-sodium control (Grummer et al., 2012). Cheese made with potassium chloride (KCl)based salt replacers had the least negative effect on flavor compared with calcium and magnesium chloride. Cheeses made with the 2 different $\mathrm{KCl}$ sources tended to be slightly more bitter than full-sodium control cheese (though the differences were not significant).

To overcome the flavor issues commonly attributed to $\mathrm{KCl}$, flavor enhancers (monosodium glutamate, hy- 
drolyzed vegetable protein, yeast extract, disodium inosinate, and disodium guanylate), sweeteners (sucrose, taumatin, and trehalose), and bitter blocking compounds are commonly paired with $\mathrm{KCl}$ in reduced sodium foods such as soups, frozen meals, processed meats, and seasoned dry snacks (Brandsma, 2006; Doyle and Glass, 2010; Henney et al., 2010). Flavor enhancers tend to contribute umami, brothy, and savory flavors to foods and can be used to create improved reduced sodium products (Reddy and Marth, 1991; Brandsma, 2006).

Published studies have not investigated the use of flavor enhancers as a means to improve the sensory characteristics of reduced sodium cheese. Studies in cheese suggest that flavors such as umami play a role in the flavor profile of cheese, as demonstrated in Drake et al. (2007), where naturally occurring glutamic acid was reported as the largest contributor to umami taste in Cheddar and Swiss. Drake et al. (2007) and Young et al. (2004) found umami intensity to increase with cheese age and to correlate positively with aged Cheddar cheese flavor attributes such as sulfur and brothy. Shakeel-Ur-Rehman et al. (2003) studied the effect of adding yeast extract at the salting step on nonstarter lactic acid bacteria in reduced fat Cheddar cheese and noted that cheese with yeast extract was perceived to have a more mature flavor than cheese without it. They also noted differences in flavor due to the addition of yeast extract, including higher sulfur, nutty, and fruity flavor intensities, as well as lower brothy flavor intensity.

We hypothesized that, by maintaining the $\mathrm{a}_{\mathrm{w}}$ of fullsodium Cheddar through the use of $\mathrm{KCl}$ in low sodium cheese, chemical and microbiological properties such as proteolysis and lactic acid bacterial counts would be equivalent. We also hypothesized that, by modifying the cheese-making procedure to reduce the moisture content of the curd, we could use less $\mathrm{KCl}$ with the same sodium content and improve the flavor of the cheese. We expected that the use of $\mathrm{KCl}$ would increase the bitterness of the cheeses and decrease consumer liking, however.

We hypothesized that the use of flavor enhancers would shift the sensory attributes of low sodium cheeses closer to the sensory attributes of full-sodium cheeses and increase consumer liking of these reduced sodium treatments. The objective of this research, therefore, was to produce $60 \%$ reduced sodium Cheddar cheese by using 2 different cheese-making procedures to allow reduced use of $\mathrm{KCl}$ - with the addition of flavor enhancers to improve sensory attributes - and to monitor cheese over the shelf-life by sensory, chemical, and microbiological methods.

\section{MATERIALS AND METHODS}

\section{Flavor Enhancer Screening}

Due to the large number of flavor enhancers available for use, screening them at various use levels before use in cheese production was desirable to minimize costs and time. Full-fat, stirred-curd Cheddar cheese was manufactured at the University of Minnesota's Joe Warthesen Food Processing Center (St. Paul), as described in Grummer and Schoenfuss (2011). Curd was either salted at the regular salting level with $\mathrm{NaCl}$ (pressed cheese contained $665 \mathrm{mg}$ of $\mathrm{Na} / 100 \mathrm{~g}$ and 89 $\mathrm{mg}$ of $\mathrm{K} / 100 \mathrm{~g}$ ), or at a reduced sodium level with both $\mathrm{NaCl}$ and $\mathrm{KCl}$ (Premier Potassium Chloride 8799, Cargill Inc., Minneapolis, MN). The reduced sodium cheese contained $386 \mathrm{mg}$ of $\mathrm{Na} / 100 \mathrm{~g}$ and $707 \mathrm{mg}$ of K/100 $\mathrm{g}$, a reduction of approximately $42 \%$ sodium from our full-sodium cheese. These 2 cheeses were aged 5 mo before being used in flavor screening.

The reduced sodium cheese was finely grated with a Waring Commercial WFP14 food processor (Conair Corp., Torrington, CT), and then $30 \mathrm{~g}$ of grated cheese was added to a Waring Commercial WSG30 spice grinder (Conair Corp.) before adding flavor enhancers at manufacturer recommended concentrations. An additional $15 \mathrm{~g}$ of cheese was added to the grinder and contents were hand-stirred for $10 \mathrm{~s}$ and then blended for approximately $30 \mathrm{~s}$, in 5-s intervals, until the mixture was homogeneous and slightly pasty. The mixture was removed from the grinder, rolled into a tight ball, and vacuum packaged with a Multivac vacuum packager (Koch, Kansas City, MO). Samples were stored at $4^{\circ} \mathrm{C}$ for $2 \mathrm{~d}$ before evaluation. The re-formed cheese had taken on the shape of a small block (approximately $8 \times 4 \times 2 \mathrm{~cm}$ ), and had knit together into a cuttable sample. The samples were cut into $1-\mathrm{cm}$ cubes for evaluation. In total, 16 flavor enhancers were screened; the concentration of the flavor enhancers screened and source information is listed in Table 1.

Seven panelists familiar with food sensory evaluation evaluated the samples blindly with a full-sodium control sample as a reference. Two of the panelists had manufactured and evaluated cheese and dairy products for over $20 \mathrm{yr}, 3$ panelists were graduate students working on dairy product research projects, and 2 panelists were students that had worked on projects involving sensory evaluation. All were familiar with the sensory terms used to describe the cheese but were not trained to quantify these flavors for this screening. Samples were evaluated for characteristics such as buttery, beefy, brothy/umami, unclean, fruity, and process cheese-like. Eight enhancers were selected, by consensus, for further evaluation at different use levels. 
Table 1. Product information and concentration of flavor enhancers ( $\mathrm{g}$ of enhancer/100 $\mathrm{g}$ of cheese) used in initial screening

\begin{tabular}{|c|c|c|c|c|}
\hline Supplier & Product name & $\begin{array}{l}\text { Product } \\
\text { description }\end{array}$ & $\begin{array}{l}\text { Concentration, } \\
\mathrm{g} / 100 \mathrm{~g}\end{array}$ & Flavor description \\
\hline Innova $^{1}$ & Sav Nat Fl Enhancer 0188404 & $\mathrm{HVP}^{2} / \mathrm{YE}^{3}$ & 0.131 & Umami/brothy, salty \\
\hline Innova & Sav Salt Reducer/Enhancer 0188807 & $\mathrm{YE}$ & 0.131 & Umami/brothy, Cheddar \\
\hline Innova & Sav Salt Reducer/Enhancer 0189154 & YE and natural flavor & 0.131 & Unclean, salty \\
\hline Innova & Sav MSG Replacer 0187641 & $\mathrm{HVP} / \mathrm{YE} / \mathrm{IMP}^{4} / \mathrm{GMP}^{5}$ & 0.075 & Process cheese, low bitter \\
\hline David Michael $^{6}$ & 50/50 Disodium Inosinate/Disodium Guanylate & IMP/GMP blend & 0.225 & Beefy, umami/brothy, unclean \\
\hline David Michael & DM Choice Natural Flavor "Potassium Blocker Type" & Natural flavor & 0.146 & Clean, nondescript \\
\hline Gold Coast $^{7}$ & Natural Salt Replacer \#2 (\#319678) & Salts, sugar, natural flavors, and whey & 0.150 & Buttery, astringent \\
\hline Gold Coast & Natural Salt Replacer \#3 (\#319679) & YE, natural flavor & 0.150 & Cheddar, salty \\
\hline Edlong $^{8}$ & Natural Cheddar-Type Flavor \#1411344-Powder & Natural flavor & 0.249 & Unclean, musty \\
\hline Edlong & Natural Masking Flavor \#1411308-Powder & Natural flavor & 0.200 & Process cheese, bland \\
\hline Edlong & Natural and Artificial Masking Flavor \#1411662-Powder & Natural and artificial flavor & 0.200 & Fruity, fruit punch \\
\hline Edlong & Natural Cheddar Flavor WONF \#1411086-Spray Dry & Natural flavor & 0.498 & Unclean, metallic \\
\hline Edlong & Natural Cheese Flavor WONF \#2406-Powder & Natural flavor & 0.249 & Umami/brothy, astringent, less salty \\
\hline Ajinomoto $^{9}$ & AJITIDE IMP Disodium $5^{\prime}$ Inosinate & IMP & 0.233 & Beefy, umami/brothy \\
\hline Balchem $^{10}$ & Flavorshure C-Salt CC98 & Choline chloride & 0.100 & Buttery \\
\hline $\begin{array}{l}\text { Premium } \\
\text { Ingredients }{ }^{11}\end{array}$ & CJTIDE Disodium 5' Guanylate & GMP & 0.233 & Buttery \\
\hline
\end{tabular}

${ }^{1}$ Innova, Lombard, IL.

${ }^{2} \mathrm{HVP}=$ hydrolyzed vegetable protein.

${ }^{3} \mathrm{YE}=$ yeast extract.

${ }^{4} \mathrm{IMP}=$ disodium $5^{\prime}$ inosinate.

${ }^{5} \mathrm{GMP}=$ disodium $5^{\prime}$ guanylate

${ }^{6}$ David Michael \& Co., Philadelphia, PA

${ }^{8}$ Edlong Corp., Elk Grove Village, IL.
${ }^{9}$ Ajinomoto Food Ingredients LLC, Chicago, IL.

${ }^{10}$ Balchem Corp., New Hampton, NY.

${ }^{11}$ Premium Ingredients International (US) LLC, Carol Stream, IL. 
Table 2. Flavor screening results of flavor enhancers ( $\mathrm{g}$ of enhancer/100 $\mathrm{g}$ of cheese) applied to reduced sodium, Cheddar-like cheese containing potassium chloride

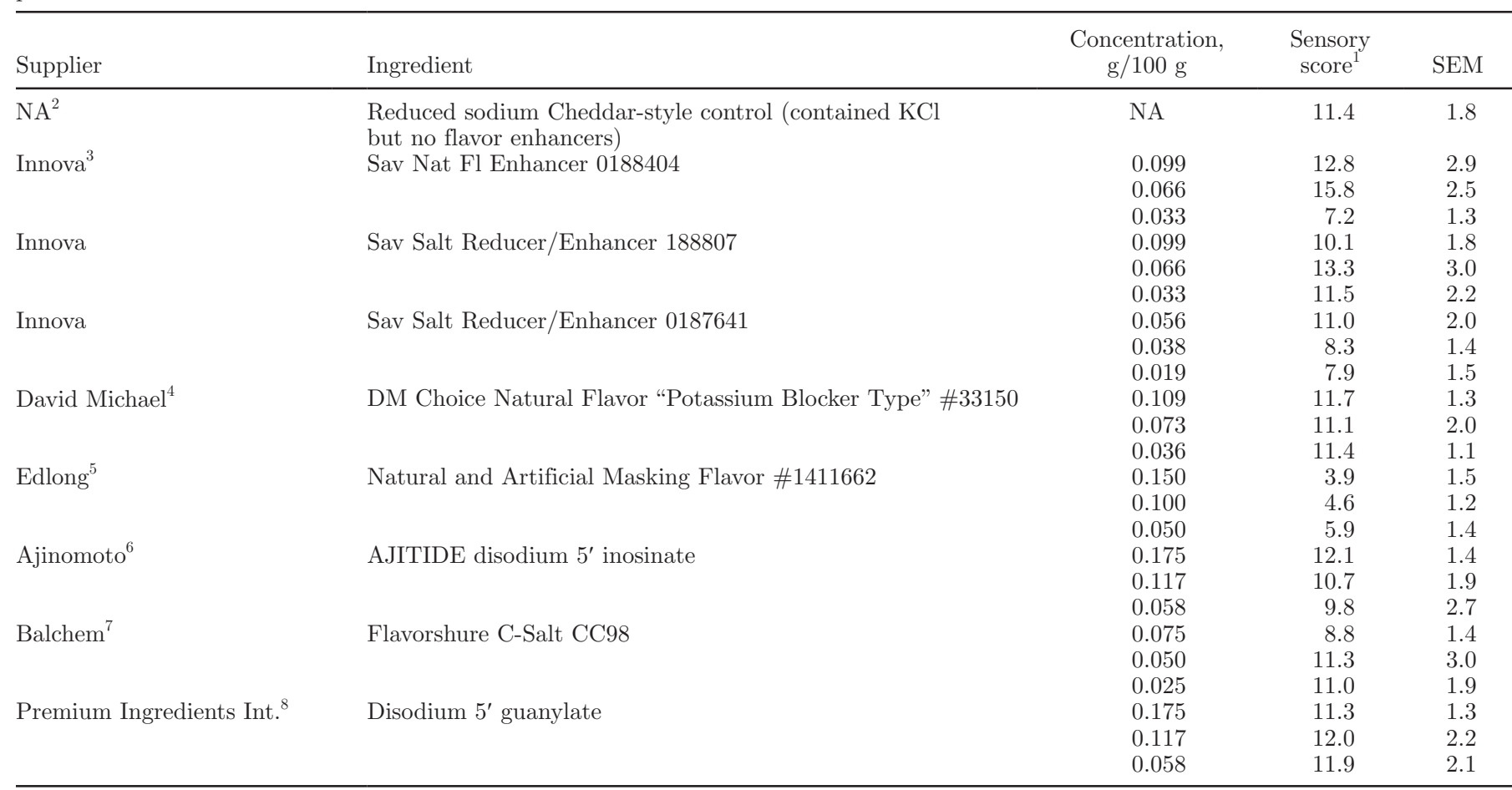

${ }^{1}$ Mean of panelist scoring quality on a 16.8 -cm line scale $(n=7)$. Highest possible score $=16.8$, lowest possible score $=0$.

${ }^{2}$ Not applicable.

${ }^{3}$ Innova, Lombard, IL.

${ }^{4}$ David Michael \& Co., Philadelphia, PA.

${ }^{5}$ Edlong Corp., Elk Grove Village, IL.

${ }^{6}$ Ajinomoto Food Ingredients LLC, Chicago, IL.

${ }^{7}$ Balchem Corp., New Hampton, NY.

${ }^{8}$ Premium Ingredients International (US) LLC, Carol Stream, IL.

The concentrations of the 8 selected enhancers were applied to cheese as previously described at levels reduced by 25, 50 and $75 \%$ from the initial screening. This was due to comments from panelists indicating that the concentrations of the flavor enhancers were too high. The concentrations of enhancers applied are shown in Table 2 . The same 7 panelists evaluated the samples in blind taste tests over 3 sessions and scored samples individually, based on similarity to full-sodium control cheese. Room temperature $\left(\sim 22^{\circ} \mathrm{C}\right)$ cheese samples were presented in 2-ounce soufflé cups with 3 -digit codes. Panelists marked their rating of overall Cheddar cheese flavor quality, ignoring other factors such as texture, on a 16.8-cm line scale anchored with "poor quality" on the left end (score of 0) and "excellent quality" (score of 16.8) on the right end. Full-sodium control cheese made with sodium chloride was presented as a high-quality reference and marked on the scale at $12.5 \mathrm{~cm}$ from the left. No training was conducted to define high and low quality, but, as mentioned previously, panelists were either highly experienced cheese makers or students and consumers of Cheddar cheese. Sensory scores for each sample were determined by measuring the distance (in $\mathrm{cm}$ ) of the marked evaluation from the left end of the scale. Based on the scores shown in Table 2, and with consideration of the ingredient type (to have a variety of enhancer types), flavor enhancers and their concentrations were selected to use in trials.

\section{Cheese Making Trials}

Cheddar-style, stirred-curd cheese was manufactured with 2 different make procedures (standard and alternate), in duplicate, at the University of Minnesota's Joe Warthesen Food Processing Center. The original goal of the alternate make procedure was to generate a lower moisture concentration that would allow reduced use of $\mathrm{KCl}$ at the $\mathrm{a}_{\mathrm{w}}$ matching that of the targeted sodium level. Approximately $2,160 \mathrm{~kg}$ of raw whole milk was pasteurized at $73.3^{\circ} \mathrm{C}$ for $16 \mathrm{~s}$ on a plate and 
frame-style milk pasteurizer and pumped into a Damrow rectangular open vat (Tetra Damrow, Vernon Hills, $\mathrm{IL})$ at $31.1^{\circ} \mathrm{C}$. One day before cheese making, a directto-vat-set culture of Lactococcus lactis ssp. cremoris and Lactococcus lactis ssp. lactis (Choozit Superstart M30, Danisco USA Inc., Madison, WI) was added to pasteurized whole milk at 1\% (wt/wt) and cultured at $22.2^{\circ} \mathrm{C}$ for $16 \mathrm{~h}$ to create a bulk culture. One hour before renneting, bulk starter was added at $1 \%$ (wt/wt) with gentle agitation. Twenty minutes before renneting, $0.02 \%$ (wt/wt) of calcium chloride (Cal-Sol 71257, Chr. Hansen Inc., Milwaukee, WI) and $0.0066 \%$ (wt/ wt) annatto (AFC W/S 1X 70463, Chr. Hansen Inc.) were added to the cheese milk. After a $\mathrm{pH}$ decrease in the milk of 0.1 to 0.15 , liquid chymosin (Chy-Max 73863 , Chr. Hansen Inc.) was added at $0.01 \%$ of the cheese milk. The vat was allowed to coagulate until the gel was set (approximately $30 \mathrm{~min}$ ), and cut with 9.5-mm wire knives for standard, and 6.4-mm knives for the alternative cheese make. After allowing the curd to heal, curd and whey for both makes were gradually heated while stirring to $39^{\circ} \mathrm{C}$ over a 30 -min period. Temperature was maintained and stirring continued for $1.5 \mathrm{~h}$, during which approximately $60 \%$ of the whey was drained in 3 intervals. The majority of the remaining whey was drained once the titratable acidity (TA) of the whey reached 0.16 to $0.17 \%$ (lactic acid basis); enough whey was maintained in the vat to prevent the curd from drying. Curd was stirred until the TA reached a target of either 0.21 (standard make), or 0.25 (alternate make), at which point curd was weighed into perforated tubs and salted with $\mathrm{NaCl}$ only (Top-Flo Evaporated Salt, Cargill Inc.), $\mathrm{NaCl}$ and 1 of the $2 \mathrm{KCl}$ types [KCl1 (Premier Potassium Chloride 8799, Cargill Inc.) or KCl2 (Modified Potassium Chloride 14510, $\mathrm{Nu}$-Tek Products Inc., Minnetonka, MN)], or $\mathrm{NaCl}$ with KCl1 plus 1 of 4 flavor enhancers (Table 3). Flavor enhancers used were hydrolyzed vegetable protein/ yeast extract blend Savor Notes Savory Natural Flavor Enhancer 0188404 (HY; Innova, Lombard, IL); DM Choice Natural Flavor "Potassium Blocker Type" 33150 Powder (PB; David Michael \& Co., Philadelphia, PA); disodium $5^{\prime}$ inosinate (I; AJITIDE IMP, Ajinomoto Food Ingredients LLC, Chicago, IL); or disodium 5' guanylate (G; CJTIDE, PT CJ, Jakarta, Indonesia).

Concentrations of $\mathrm{KCl} 1$ and $\mathrm{KCl} 2$ were determined by measuring the concentrations found to produce equivalent $\mathrm{a}_{\mathrm{w}}$ between low- and full-sodium model cheese as described in Grummer and Schoenfuss (2011). The differences between $\mathrm{NaCl}$ and $\mathrm{KCl}$ concentrations in the standard and alternate make procedures were in place because lower moisture was expected in the final cheese of the alternate make procedure; so, less $\mathrm{NaCl}$ could be added to still be low sodium and less $\mathrm{KCl}$

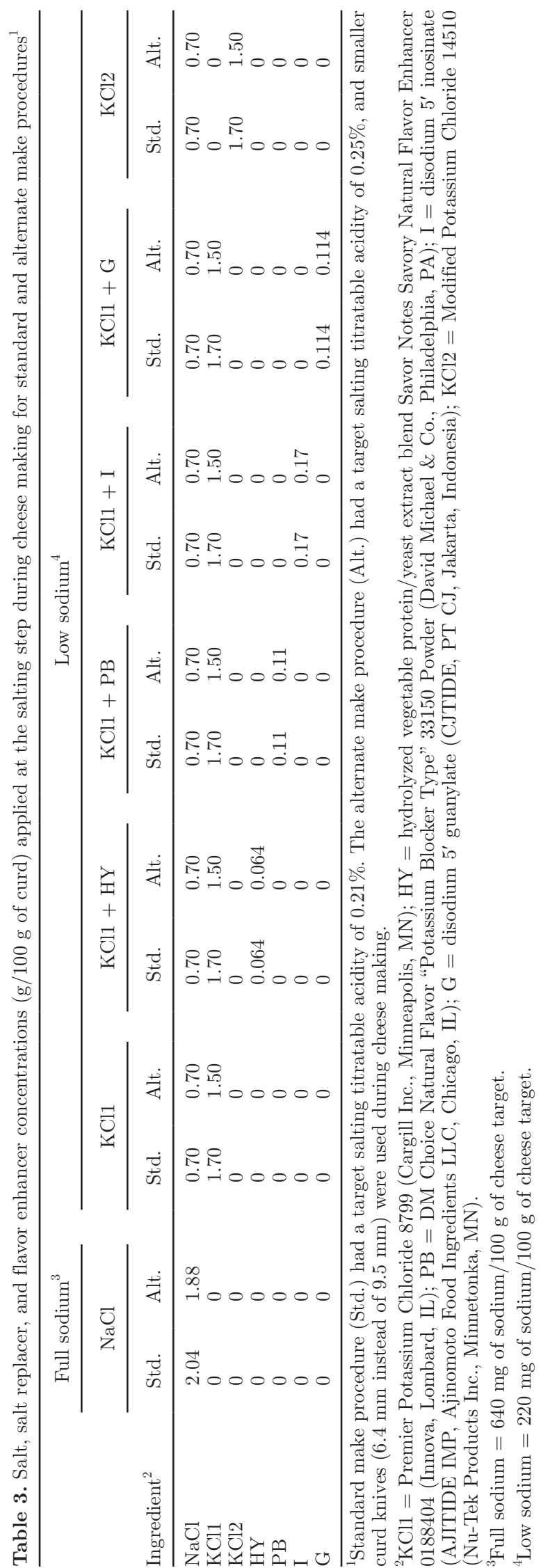

Journal of Dairy Science Vol. 96 No. 3, 2013 
would be needed to maintain equivalent $\mathrm{a}_{\mathrm{w}}$. Salt, $\mathrm{KCl}$, and flavor enhancers were preblended and divided into 3 equal portions that were applied at 5-min intervals (Table 3). Curd was transferred to cheesecloth-lined, 9.1-kg Wilson-style cheese hoops and pressed overnight at $276 \mathrm{kPa}$. Blocks were vacuum packaged in a Multivac vacuum packager (Koch, Kansas City, MO) and stored at 4 to $5^{\circ} \mathrm{C}$. Cheese making was replicated for each target TA method, on $2 \mathrm{~d}$ with different lots of milk.

\section{Compositional, Chemical, and Microbial Analysis}

Moisture content, $\mathrm{pH}, \mathrm{a}_{\mathrm{w}}$, water-soluble nitrogen (WSN), and lactic acid bacteria (LAB) enumeration were measured within 2 wk of cheese making and monthly for 4 mo (mo 1, 2, 3, and 4) after cheese making. Fat, ash, protein, and mineral (sodium, potassium, magnesium, calcium) contents were measured once after 2 wk of aging.

Moisture content was determined by vacuum oven following method 15.111 in Standard Methods for the Analysis of Dairy Products (Wehr and Frank, 2004). The $\mathrm{pH}$ was measured on an Acorn $\mathrm{pH} 6$ Meter (Oakton Instruments, Vernon Hills, IL) with an Orion 8172BNWP Ross Sure-Flow pH electrode (Thermo Fisher Scientific Inc., Waltham, MA). Water activity was measured at $23^{\circ} \mathrm{C}$ on an Aqua Lab 3TE a meter (Decagon Devices, Pullman, WA $)$. Total protein $(\%$ nitrogen $\times 6.38)$ was determined using the TruSpec $\mathrm{N}$ nitrogen analyzer (Leco Corporation, St. Joseph, MI) based on the Dumas method of combustion. The WSN method was based on the method of Kuchroo and Fox (1982), followed by nitrogen analysis using a TruSpec N; WSN was expressed as the percentage of the total nitrogen in the cheese that was soluble in the extract. Counts of LAB were based on method 8.071 (total LAB method; Wehr and Frank, 2004) by streak-plating on Lactobacilli MRS agar (Difco Laboratories, Detroit, MI) with a flame-sterilized hockey stick. Fat and ash content were determined following methods 18.8A2c and 18.4A, respectively (Richardson, 1985). Sodium, potassium, magnesium, and calcium content were measured by atomic absorption spectrometry using a PerkinElmer AAnalyst 100 (PerkinElmer, Waltham, MA) using IDF method 119:2007(E) (ISOIDF, 2007), but incorporating the wet ashing method of Kira et al. (2004) for sample preparation. Particle size of the $\mathrm{KCl}$ ingredients was measured on Malvern Mastersizer S with 2-propanol as the dispersion media and software version 2.18 (Malvern Instruments Ltd., Malvern, UK). All measurements were performed in duplicate at minimum.

\section{Statistical Analysis of Compositional, Chemical, and Microbial Analysis}

To determine whether compositional, chemical, or microbial measurements differed among cheeses, we used linear mixed model ANOVA with LSD as multiple comparisons tests $(P<0.05$; SPSS Statistics ver. 17.0.2, IBM SPSS, Chicago, IL). To determine relationships among these measurements we computed Pearson correlations among the means of all measurements that differed significantly among the cheese treatments using XLSTAT version 2011.1.04 (Addinsoft USA, New York, NY).

\section{Descriptive Sensory Analysis}

Subjects. Ten members of the trained descriptive analysis panel from the Sensory Center at the University of Minnesota participated in the tests. From 6 to 10 of these panelists participated at each series of monthly test sessions. All were 6-n-propylthiouracil tasters or supertasters, and were compensated for participating. All recruiting and experimental procedures were approved by the University of Minnesota's Institutional Review Board.

Products. A total of 14 cheeses were included, consisting of the 7 treatments from both cheese make replicates. Each panelist received 3 cubes $\left(1.5 \mathrm{~cm}^{3}\right)$ of each cheese in a 4-ounce plastic cup with a random 3 -digit code on the lid. Products were held at $4^{\circ} \mathrm{C}$ until $1 \mathrm{~h}$ before serving, at which point they were allowed to warm to room temperature $\left(\sim 22^{\circ} \mathrm{C}\right)$.

Training. Panelists participated in 3 training sessions to familiarize themselves with the test cheeses. In each training session the panelists received a previously developed lexicon (Supplemental file, available at http://www.journalofdairyscience.org/). Taste, flavor, aroma, texture, and other sensation references used for the descriptive sensory analysis are listed in the lexicon. All chemicals were Food Chemicals Codex (FCC) or United States Pharmacopeia Convention (USP) approved. Panelists individually described several pairs of the test cheeses using the lexicon. They then participated in a group discussion about the rating intensities of the sensory attributes for each cheese and clarified definitions of the established references.

Experimental Procedure. Panelists evaluated the cheeses at 1-mo intervals, thus participating in a total of 16 testing sessions (4 sessions per week for $1 \mathrm{wk}$ at the end of each month of the 4-mo aging period). Panelists evaluated a complete set of the 14 samples (7 from each of the 2 cheese make procedures) during the 
first 2 sessions of each testing week. This was repeated during the second 2 sessions of the week to serve as a sensory replicate (mo 3 tests did not include the sensory replicate). Within a group of 2 sessions, serving orders were balanced for position and carryover effects. During the testing sessions each panelist evaluated samples by rating the intensity of the attributes on 20-point line scales labeled "none" at the left end and "intense" at the right end. Intensity ratings of flavor and taste were made on a standard citric acid scale using concentrations of, $0.05,0.075$, and $0.15 \%$ to represent intensities of 2,5 , and 10 , respectively. Ratings of odors were made on the standard butanol scale (ASTM, 2010). Texture ratings were made on a 20-point scale, anchored with references. Panelists were instructed to wear nose clips when evaluating the taste attributes.

Data Analysis. We used SAS PROC GLM (version 9.2; SAS Institute Inc., Cary, NC) to determine whether the samples differed in any of the sensory attributes. The attribute intensity was the dependent variable; product, month, make, replicate, panelist, product $\times$ month, product $\times$ make, and product $\times$ make $\times$ month were predictors. Student-Newman-Keuls tests were used to determine significance within specific variables $(\alpha<0.05)$.

We used principal component analyses (XLSTAT version 2011.1.04; Addinsoft USA) with a Varimax rotation to summarize the differences in sensory attributes among the cheeses and to relate these sensory attributes to the product age, to the make procedures, to the instrumental measurements, and to the consumer liking ratings as follows:

For comparisons among 4-mo-old cheeses, make procedures, and instrumental measurements, we input the mean sensory attribute ratings from mo 4 for all 7 cheeses and both makes (a total of 14 observations), and the 19 sensory attributes that differed significantly among these cheeses at mo 4. The 10 instrumental measurements were added as quantitative supplementary variables, and make procedure was added as a supplementary qualitative variable. For comparisons among the 4-mo-old cheeses, make procedures, and consumer liking ratings, we used the same strategy as for the instrumental measurements, but substituted the consumer liking ratings for the instrumental measurements. For comparisons of the sensory attributes among the cheeses at 1, 2, 3, and 4 mo of age, we input the mean sensory attribute ratings from mo 1 to 4 for all 7 cheeses and both makes (a total of $14 \times 4$ $=56$ observations), and the 29 sensory attributes that differed significantly among these cheeses and makes over the 4-mo storage period. Storage month and make procedure were added as a supplementary quantitative and qualitative variables.

\section{Consumer Acceptability Test}

Subjects. The University of Minnesota's Sensory Center recruited 117 judges including students and staff who had expressed interest in participating in sensory tests. Panelists were $18 \mathrm{yr}$ of age or older, had no food allergies or sensitivities, and had consumed Cheddar cheese within the month before testing. They were paid for participating. The University of Minnesota's Institutional Review Board approved all recruiting and experimental procedures.

Products. A total of 14 cheeses were included, representing each of the 7 treatments from each of the make procedures aged for 4 mo. Panelists received 2 cubes $\left(1.5 \mathrm{~cm}^{3}\right)$ of each cheese at room temperature in coded and lidded cups. Products were refrigerated until $1 \mathrm{~h}$ before serving.

Experimental Procedure. Sample orders were balanced for position and carryover effects. Subjects were asked to take one bite of the sample and rate it for overall liking, liking of flavor, and liking of texture. Liking ratings were made on 120-point labeled affective magnitude scales, with the left end labeled "greatest imaginable disliking" and the right end labeled "greatest imaginable liking." Panelists were then instructed to take a second bite of the sample and rate the intensity of any off flavor. This rating was made on a 20-point line scale with the left-most end labeled "none" and the right-most end labeled "extremely intense."

Data Analysis. To determine whether the samples differed in any of the attributes, we used a mixed model ANOVA (SAS PROC MIXED ver. 9.2; SAS Institute Inc., Cary, NC) with the sensory ratings as dependent variables and product as a fixed predictor. Subject was a random predictor in the models. We used a Bonferroni correction to determine whether specific differences among samples were significant $(P<0.05)$.

\section{RESULTS}

\section{Effect of $\mathrm{KCl}$ Source and Cheese-Making Procedure on Chemical and Microbial Composition}

The $2 \mathrm{KCl}$ salt replacers behaved differently in the standard make procedure in regard to syneresis, resulting in moisture, fat, and protein concentration differences (Tables 4 and 5). This was not observed in the alternate make procedure, however.

The $\mathrm{a}_{\mathrm{w}}$ of all cheeses declined over time, but no differences were observed between treatments or make procedures (Figure 1). The $\mathrm{pH}$ of $\mathrm{KCl} 2$ in both make procedures was consistently lower than in the corresponding cheeses with KCl1 (Figure 2). Changes in $\mathrm{pH}$ over time (Figure 2; Table 4) were also noted. The $\mathrm{pH}$ 
Table 4. Main and interaction effects of all treatments (Trt), time, and make procedure (MP) on compositional, chemical, and microbial measurements of low sodium, Cheddar-style cheese

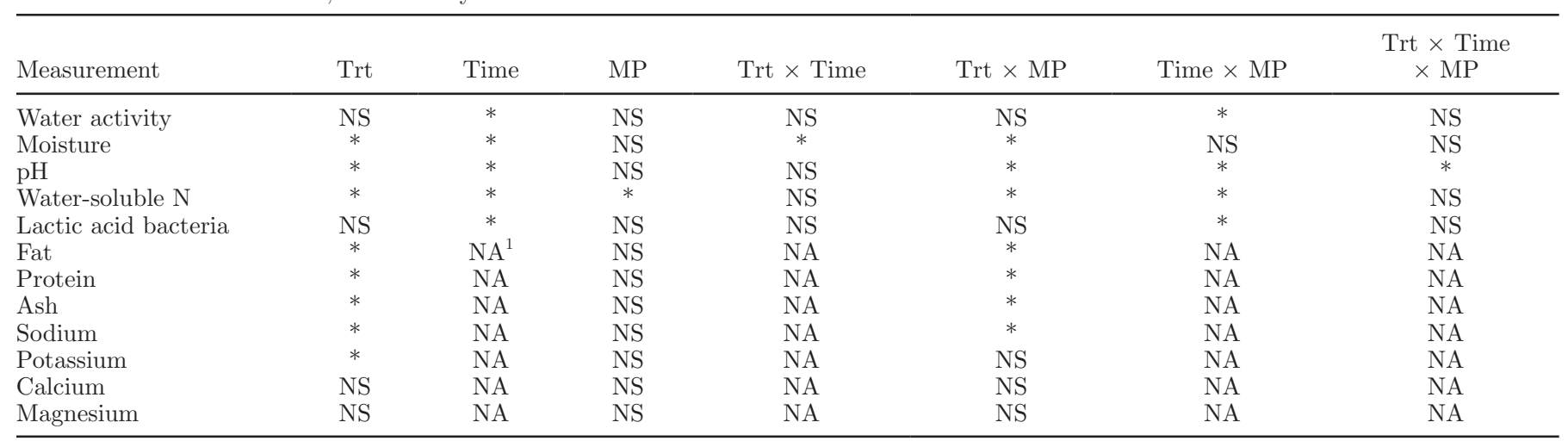

${ }^{1}$ Not applicable.

$* P<0.05$.

of the full-sodium, standard make cheese was higher than the other treatments but not the full-sodium alternate make.

Proteolysis, as indicated by WSN, increased with time for all treatments (Figure 3; Table 4). Water-soluble nitrogen was higher in treatments containing $\mathrm{KCl} 2$ than treatments with $\mathrm{KCll}$ and for treatments made with the alternate make procedure compared with the standard make procedure.

Counts of bacteria enumerated on Lactobacillus MRS agar declined significantly over time during the aging period, and the alternate make procedure had lower counts than the standard make procedure later in the aging period. This resulted in the statistical difference in the time by make procedure interaction (Table 4).

\section{Effect of $\mathrm{KCl}$ Source, Cheese-Making Procedure, and Flavor Enhancers on Sensory Properties}

Figures 4, 5, 6, 7, and 8 show results of principal component analyses. Descriptive analysis panelists generally rated the full- $\mathrm{NaCl}$ cheeses lower in overall flavor, sulfur flavor, sourness, bitterness, and stickiness than the cheeses with $\mathrm{KCl}$ (Figure 5). They rated KCl1

Table 5. Composition data of Cheddar cheese

\begin{tabular}{|c|c|c|c|c|c|c|}
\hline Measurement & \multicolumn{6}{|c|}{ Treatment $^{1}$} \\
\hline Moisture, ${ }^{4} \%$ & $38.65^{\mathrm{b}}$ & $37.92^{\mathrm{bc}}$ & $37.61^{\mathrm{c}}$ & $37.74^{\mathrm{bc}}$ & $40.67^{\mathrm{a}}$ & $38.69^{\mathrm{b}}$ \\
\hline Fat, $\%$ & $33.0^{\mathrm{c}}$ & $33.8^{\mathrm{ab}}$ & $33.1^{\mathrm{bc}}$ & $33.9^{\mathrm{a}}$ & $31.5^{\mathrm{d}}$ & $33.4^{\mathrm{abc}}$ \\
\hline Protein, \% & $24.73^{\mathrm{a}}$ & $24.45^{\mathrm{a}}$ & $24.69^{\mathrm{a}}$ & $24.45^{\mathrm{a}}$ & $23.36^{\mathrm{b}}$ & $23.95^{\mathrm{b}}$ \\
\hline $\mathrm{K}, \mathrm{mg} / 100 \mathrm{~g}$ & $83.7^{\mathrm{c}}$ & $81.1^{\mathrm{c}}$ & $674.2^{\mathrm{a}}$ & $676.1^{\mathrm{a}}$ & $656.0^{\mathrm{a}}$ & $558.3^{\mathrm{b}}$ \\
\hline $\mathrm{Ca}, \mathrm{mg} / 100 \mathrm{~g}$ & 232.5 & 217.2 & 240.7 & 219.9 & 233.3 & 211.0 \\
\hline $\mathrm{Mg}, \mathrm{mg} / 100 \mathrm{~g}$ & 8.6 & 8.8 & 8.8 & 10.5 & 9.3 & 10.2 \\
\hline Effective salt to moisture ratio ${ }^{5}$ & 4.03 & 3.47 & 4.13 & 4.18 & 3.91 & 3.45 \\
\hline
\end{tabular}

${ }^{\mathrm{a}-\mathrm{d}}$ Means without a common superscript letter within the same row are significantly different $(P<0.05)$.

${ }^{1} \mathrm{Std} .=$ standard make procedure with a target salting titratable acidity of 0.21 ; Alt. $=$ alternate make procedure with a target salting titratable acidity of $0.25 \%$ and smaller curd knives $(6.4 \mathrm{~mm}$ instead of $9.5 \mathrm{~mm})$ used during cheese making; KCl1 = Premier Potassium Chloride 8799 (Cargill Inc., Minneapolis, MN); KCl2 = Modified Potassium Chloride 14510 (Nu-Tek Products Inc., Minnetonka, MN).

${ }^{2}$ Full sodium $=620 \mathrm{mg}$ of sodium $/ 100 \mathrm{~g}$ of cheese target.

${ }^{3}$ Low sodium $=220 \mathrm{mg}$ of sodium/100 g of cheese target.

${ }^{4}$ Moisture measured at mo 1.

${ }^{5}$ Salt to moisture calculated by multiplying $\mathrm{Na}$ and $\mathrm{K}$ concentrations by 2.54 and 2.18 , respectively, to obtain the $\mathrm{NaCl}$ and $\mathrm{KCl}$ concentrations. $\mathrm{KCl}$ concentration was divided by 1.27 to determine the equivalent amount of $\mathrm{NaCl}$ in terms of molar concentration. This value was added to the actual $\mathrm{NaCl}$ and divided by the moisture in the sample to determine the effective salt to moisture. Naturally occurring $\mathrm{K}$ was subtracted from the calculations. 


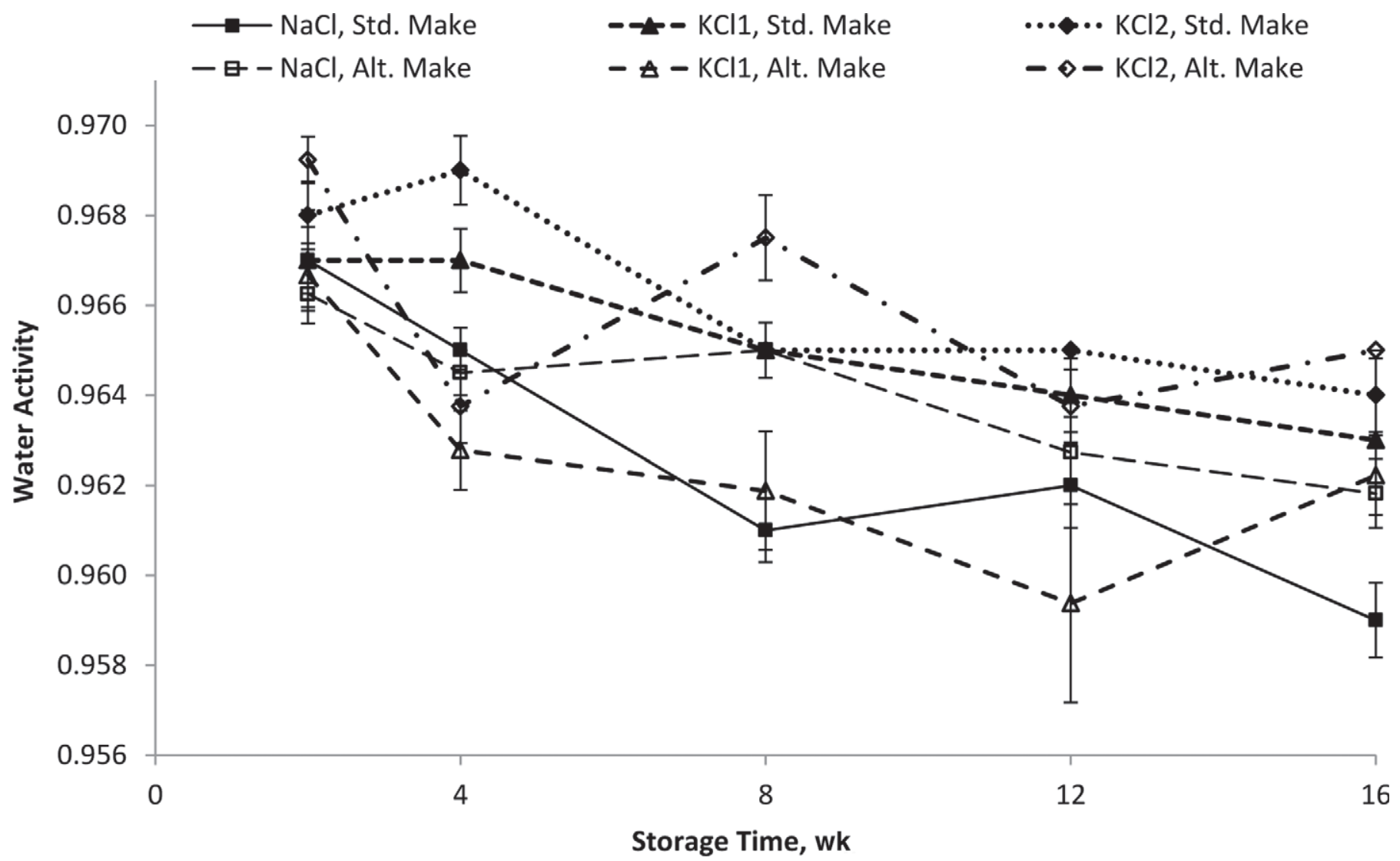

Figure 1. Change in water activity through 16 wk of aging. Standard make procedure (Std.) had a $0.21 \%$ titratable acidity, and alternate make procedure (Alt.) had a target titratable acidity of $0.25 \%$ and smaller curd knives were used during cheese making (6.4 vs. $9.5 \mathrm{~mm}$ ). NaCl Std. make $=640 \mathrm{mg}$ of sodium $/ 100 \mathrm{~g}$ of cheese target: KCl1 Std. make = sodium chloride + KCl1 (Premier Potassium Chloride 8799 , Cargill Inc., Minneapolis, MN; $220 \mathrm{mg}$ of sodium/100 g); KCl2 Std. make = sodium chloride + KCl2 (Modified Potassium Chloride 14510, Nu-Tek Products Inc., Minnetonka, MN; $220 \mathrm{mg}$ of sodium/100 g); NaCl Alt. make = (640 mg of sodium/100 g); KCl1 Alt. make = sodium chloride + KCl1 (220 mg of sodium/100 g); KCl2 Alt. make = sodium chloride + KCl2 (220 mg of sodium/100 g). Error bars indicate standard errors.

+ I higher for brothy flavors. The principal component analysis of the 4-mo old cheeses summarizes these relationships (Figures 5 and 6).

Principal component 1, which explained $29 \%$ of the variance in the data set, was positively related to brittleness and firmness and negatively related to overall flavor intensity and to stickiness. Sodium chloride scored relatively low on this attribute; KCl1-PB and KCl1-HY scored relatively high (Figure 4). Component 2 , which explained $18 \%$ of the variance, was positively related to sour and to sulfur flavor; $\mathrm{NaCl}$ scored relatively low on this component (Figure 4) Component 3, which explained $16 \%$ of the variance, correlated positively with umami taste and with brothy aroma and flavor and correlated negatively with diacetyl. Panelists scored KCl1-I highly on this component; scores for $\mathrm{NaCl}, \mathrm{KCl1}$, and KCL1-HY were relatively low (Figure $5)$. Component 4 , which explained $15 \%$ of the variance, correlated positively with salty taste and sour dairy flavor. Standard make cheeses scored higher on this component than the alternate make cheeses (Figure 5).

\section{Effect of Aging on the Sensory Attributes of the Cheeses}

As the cheeses aged they generally became more flavorful (ratings for most flavor attributes tended to increase, especially those for sulfur, diacetyl, sour, and sour dairy). Aging shifted textures from being relatively more brittle, firm, and curdy to being relatively more sticky (Figure 7). Specifically, the principal components analysis of all products and all make procedures over the 4 mo of aging showed the following.

Component 1 was highly positively correlated with overall flavor, sulfur aroma and flavor, sour dairy flavor, and stickiness on first bite and after 5 chews. Component 1 was negatively correlated with firmness, brittleness, and curdiness after 5 chews. Aging time was positively correlated with this first component $(\mathrm{r}=0.67$; Figure 7). Component 2 was positively related to firmness and cohesiveness and negatively correlated with stickiness. The standard make was positively correlated $(\mathrm{r}=0.34)$ with component 2. Aging time was uncorrelated with 


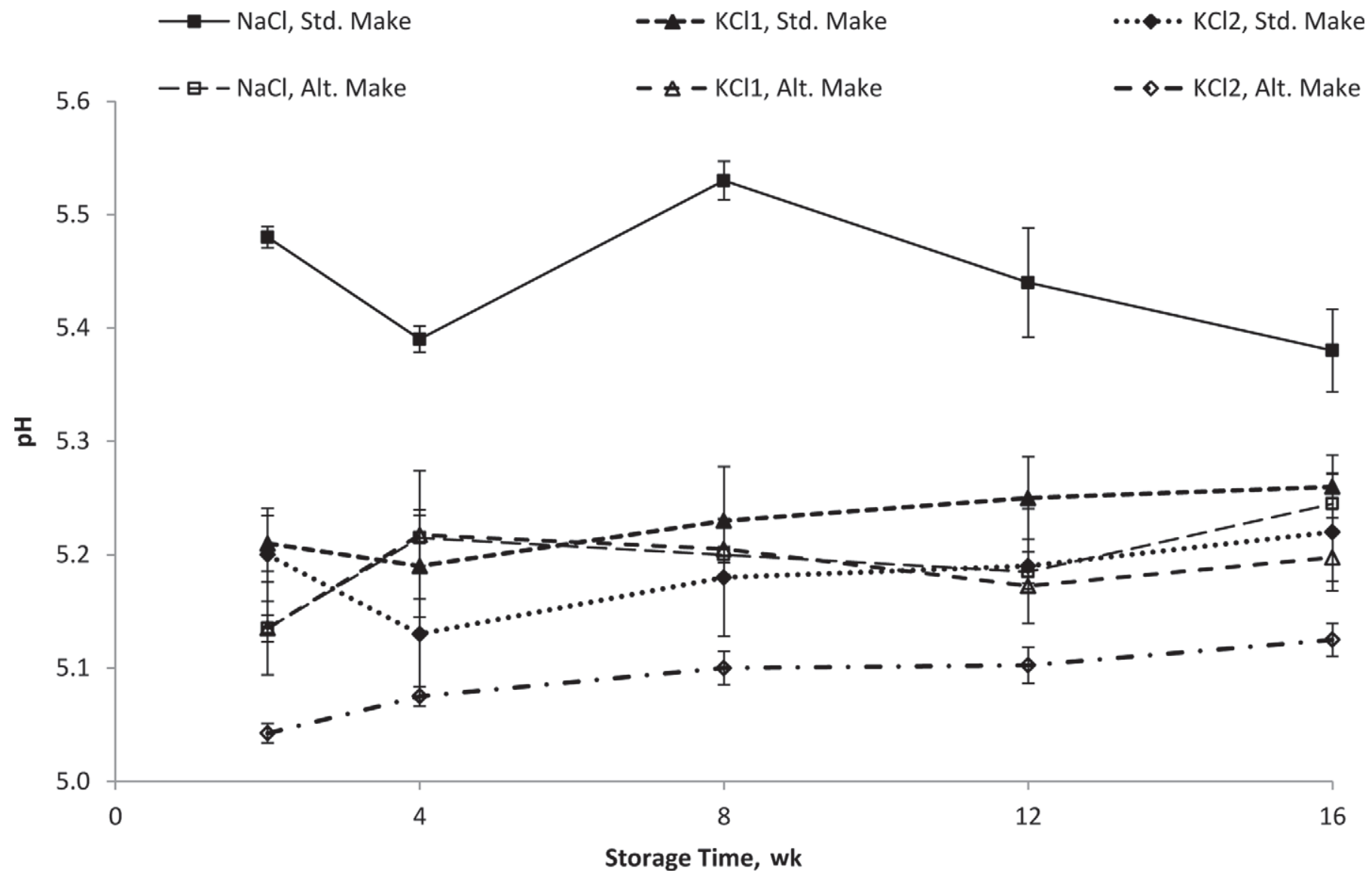

Figure 2. Change in $\mathrm{pH}$ through 16 wk of aging. Standard make procedure (Std.) had a $0.21 \%$ titratable acidity, and alternate make procedure (Alt.) had a target titratable acidity of $0.25 \%$ and smaller curd knives were used during cheese making (6.4 vs. 9.5 mm). NaCl Std. make $=640 \mathrm{mg}$ of sodium $/ 100 \mathrm{~g}$ of cheese target; KCl1 Std. make = sodium chloride + KCl1 (Premier Potassium Chloride 8799, Cargill Inc., Minneapolis, MN; $220 \mathrm{mg}$ of sodium/100 g); KCl2 Std. make = sodium chloride + KCl2 (Modified Potassium Chloride 14510, Nu-Tek Products Inc., Minnetonka, MN; $220 \mathrm{mg}$ of sodium/100 g); NaCl Alt. make = (640 mg of sodium/100 g); KCl1 Alt. make = sodium chloride + KCl1 (220 $\mathrm{mg}$ of sodium $/ 100 \mathrm{~g}) ; \mathrm{KCl} 2$ Alt. make = sodium chloride $+\mathrm{KCl} 2(220 \mathrm{mg}$ of sodium/100 g). Error bars indicate standard errors.

component 2 . The standard make was positively correlated with component 2 (Figure 7 ). Component 3 was positively correlated with cooked aroma and flavor and with slipperiness. It was negatively correlated with first bite brittleness. Aging time was positively correlated with this component $(\mathrm{r}=0.45)$, as was the standard make $(r=0.46$; Figure 8$)$. Component 4 was positively correlated with brothy flavor and umami taste; aging time was also positively correlated with this component $(\mathrm{r}=0.29)$. The standard make was negatively related to this component $(\mathrm{r}=-0.27$; Figure 8$)$.

\section{Relationships Among Products and Instrumental Measurements}

Relationships among the products and the instrumental measures are illustrated by the principal component bi-plots in Figures 5 and 6.
Principal component 1 was positively related to brittleness and firmness and negatively related to overall flavor and to stickiness. Among the instrumental measures, fat and protein had the largest positive correlations with component 1 ( $\mathrm{r}=0.5$ and 0.47 , respectively); moisture had the largest negative correlation with component $1(\mathrm{r}=-0.53$; Figure 4$)$. Component 2 was positively related to sour and to sulfur flavor. Among the instrumental measures, $\mathrm{K}$ had the largest positive correlation with component $2(\mathrm{r}=0.64) ; \mathrm{Na}$ had the largest negative correlation $(\mathrm{r}=-0.68$; Figure 4). Component 3 correlated positively with umami taste and with brothy aroma and flavor and correlated negatively with diacetyl. Among the instrumental measurements, $a_{w}$ had the highest positive correlation with component $3(\mathrm{r}=0.48)$; $\mathrm{Na}$ had the largest negative correlation ( $\mathrm{r}=-0.39$; Figure 5$)$. Component 4 correlated positively with salty taste and sour dairy fla- 

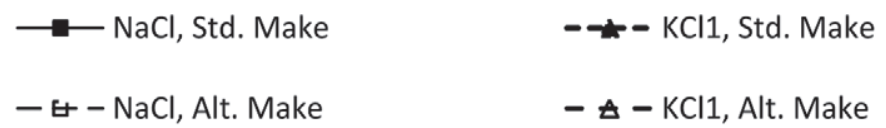

$$
\begin{aligned}
& \cdots \bullet \cdot \mathrm{KCl} 2 \text {, Std. Make } \\
& -\diamond-\mathrm{KCl} 2 \text {, Alt. Make }
\end{aligned}
$$

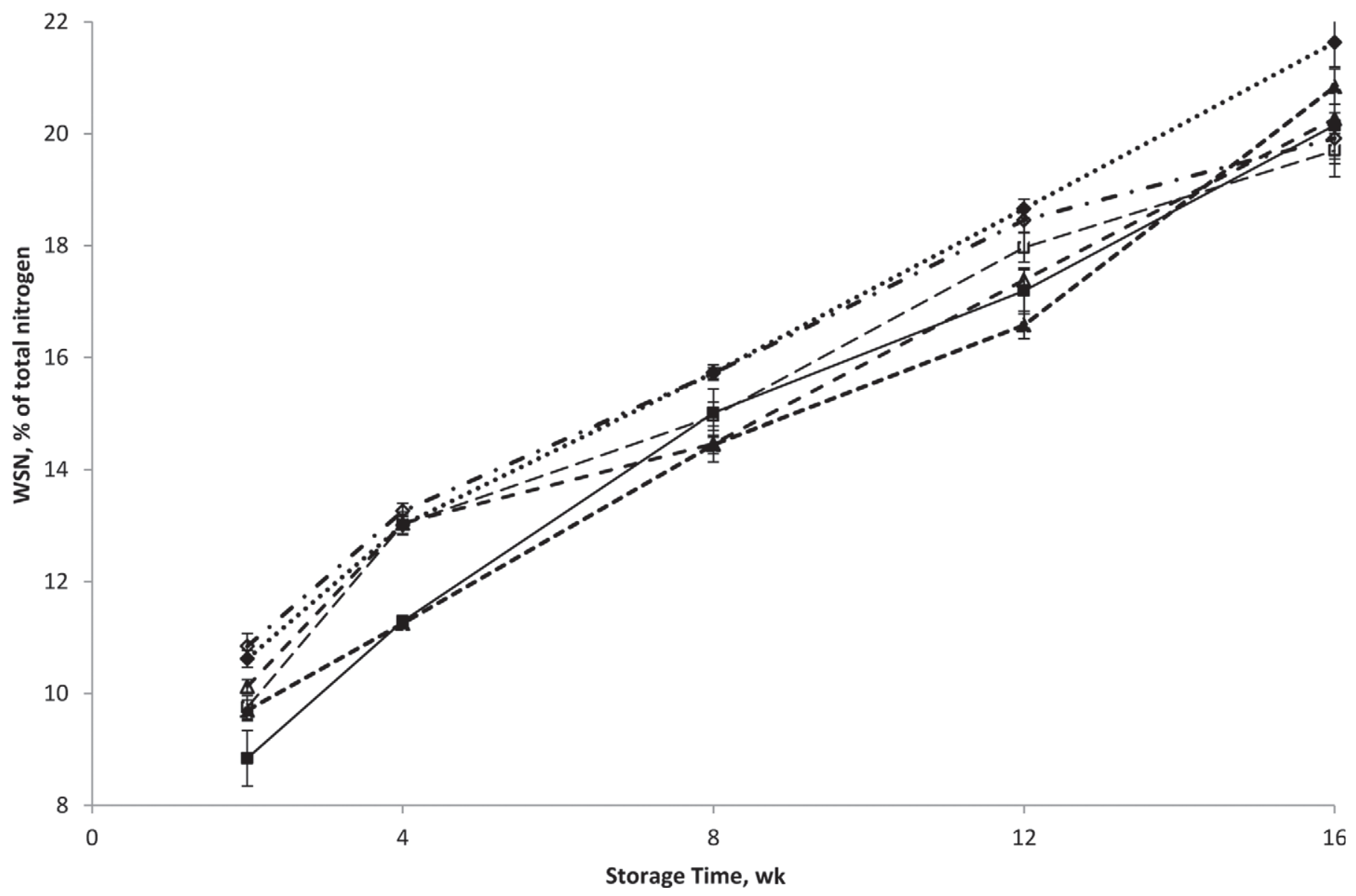

Figure 3. Change in water-soluble nitrogen (WSN) through 16 wk of aging. Standard make procedure (Std.) had a $0.21 \%$ titratable acidity, and alternate make procedure (Alt.) had a target titratable acidity of $0.25 \%$ and smaller curd knives were used during cheese making (6.4 vs. 9.5 $\mathrm{mm}$ ) $\mathrm{NaCl}$ Std. make $=640 \mathrm{mg}$ of sodium $/ 100 \mathrm{~g}$ of cheese target; KCl1 Std. make = sodium chloride + KCl1 (Premier Potassium Chloride 8799 , Cargill Inc., Minneapolis, MN; $220 \mathrm{mg}$ of sodium/100 g); KCl2 Std. make = sodium chloride + KCl2 (Modified Potassium Chloride 14510, NuTek Products Inc., Minnetonka, MN; $220 \mathrm{mg}$ of sodium/100 g); NaCl Alt. make = (640 mg of sodium/100 g); KCl1 Alt. make = sodium chloride $+\mathrm{KCl} 1$ (220 mg of sodium/100 g); KCl2 Alt. make = sodium chloride + KCl2 (220 mg of sodium/100 g). Error bars indicate standard errors.

vor. Among the instrumental measurements, LAB had the largest positive correlation with component 4 ( $\mathrm{r}$ $=0.51)$; fat had the largest negative correlation $(\mathrm{r}=$ -0.62 ; Figure 5). The standard make cheeses scored more highly on component 4 than did the alternate make cheeses (Figure 5).

\section{Relationships Among Products and Consumer Liking Ratings}

Overall liking and flavor liking were highly correlated with each other $(r=0.99)$, and both were associated with higher levels of diacetyl aroma and with lower levels of umami taste and brothy aromas and flavors.
These 2 liking measures correlated negatively ( $\mathrm{r}=$ $-0.71,-0.72$ respectively) with component 3 (Figure $6)$. Texture liking was associated with firm and brittle textures, and thus positively correlated $(\mathrm{r}=0.52)$ with component 1 (Figure 6).

\section{DISCUSSION}

Previous studies have shown little effect of the addition of $\mathrm{KCl}$ on the moisture content of Cheddar cheese when replacing $\mathrm{NaCl}$ in Cheddar (Lindsay et al., 1982; Fitzgerald and Buckley, 1985; Reddy and Marth, 1995), Kefalograviera (a hard sheep milk cheese; Katsiari et al., 1998), and feta cheeses (Aly, 1995; Katsiari et al., 


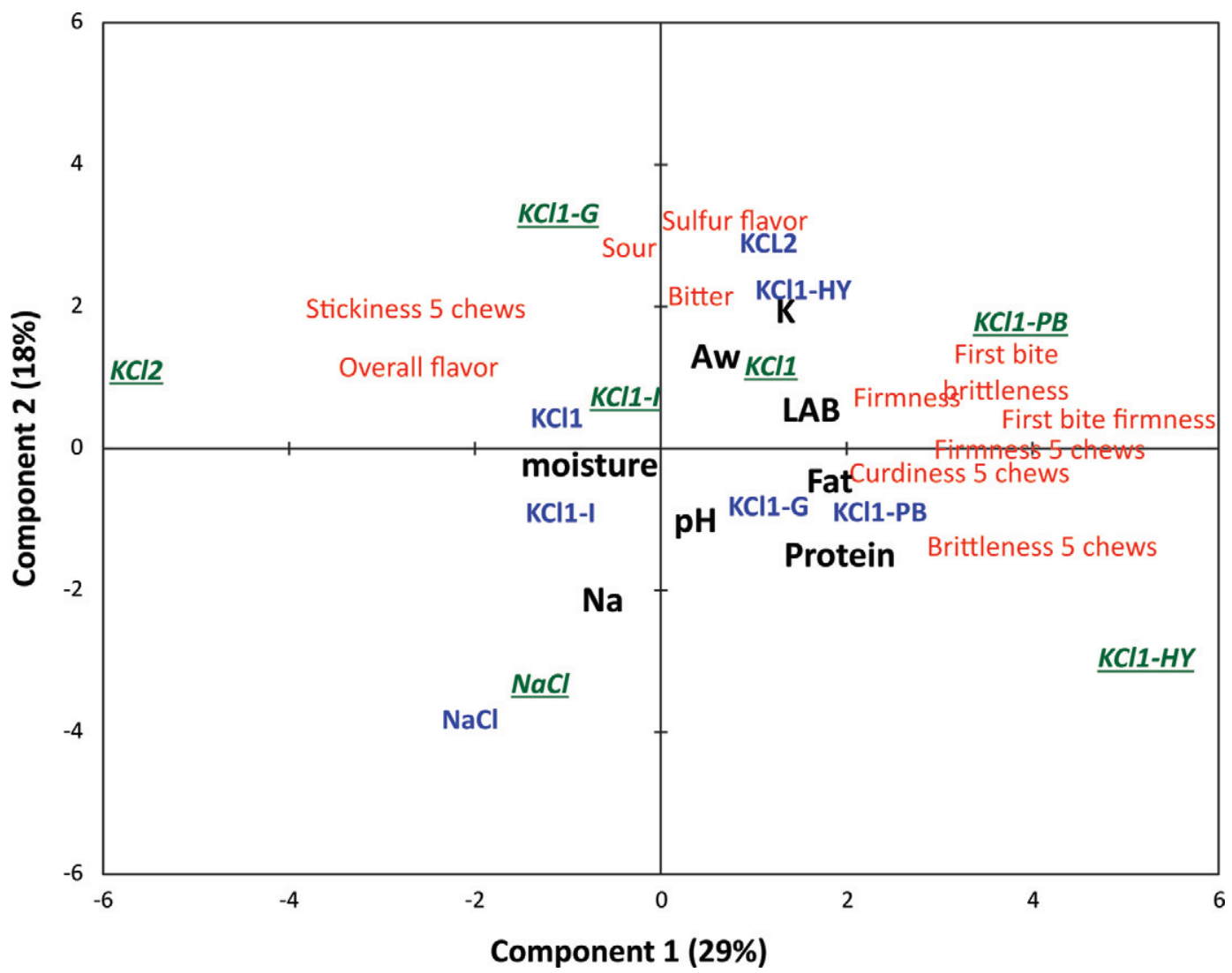

Figure 4. Plot of principal components 1 and 2 showing the position of the sensory attributes with loadings on these components $>0.6$ and the position of instrumental measurements with correlations greater than 0.3 . We input the mean sensory attribute ratings from mo 4 for all 7 cheeses and both makes (a total of 14 observations) and the 19 sensory attributes that differed significantly among these cheeses at mo 4 . The 10 instrumental measurements were added as quantitative supplementary variables; make procedure was added as a supplementary qualitative variable. Cheese names in roman font (blue) are alternate make (target salting titratable acidity of $0.25 \%$ ); cheese names in underlined italic font (green) are standard make (target salting titratable acidity of $0.21 \%$ ). Sensory attributes are in gray (red); instrumental measures are in bold (black). $\mathrm{NaCl}=640 \mathrm{mg}$ of sodium/100 g of cheese target; KCl1 = sodium chloride + KCl1 (Premier Potassium Chloride 8799 , Cargill Inc., Minneapolis, MN; $220 \mathrm{mg}$ of sodium/100 g); KCl2 = sodium chloride $+\mathrm{KCl} 2$ (Modified Potassium Chloride 14510, Nu-Tek Products Inc., Minnetonka, MN; $220 \mathrm{mg}$ of sodium/100 g); HY = hydrolyzed vegetable protein/yeast extract blend (Savor Notes Savory Natural Flavor Enhancer 0188404, Innova, Lombard, IL); PB = DM Choice Natural Flavor "Potassium Blocker Type" 33150 Powder (David Michael \& Co., Philadelphia, PA); I = disodium 5' inosinate (AJITIDE IMP, Ajinomoto Food Ingredients LLC, Chicago, IL); G = disodium 5' guanylate, (CJTIDE, PT CJ, Jakarta, Indonesia); LAB = lactic acid bacteria; Aw = water activity. Color version available in the online PDF.

1997). Reduction of $\mathrm{NaCl}$ without the use of replacement salts, or some other means of buffering, results in higher moisture, texture defects, and lack of flavor due to a combination of increased moisture and enzymatic activity in the resulting cheese (Kosikowski, 1983; Schroeder et al., 1988). In our previous study (Grummer and Schoenfuss, 2011), reduced sodium cheese with $\mathrm{KCl} 2$ was higher in moisture than both reduced sodium with KCl1 and full-sodium control cheese. The same trend was observed in this study, with the $\mathrm{KCl} 2$ cheese by the standard make procedure having higher moisture than the $\mathrm{NaCl}$ control cheese (Table 5). In fact, this cheese was above the legal maximum moisture of $39 \%$ for Cheddar in the United States. These cheeses were targeted to have enough $\mathrm{KCl}$ to create equivalent $\mathrm{a}_{\mathrm{w}}$, but it is evident that differences in the
$\mathrm{KCl}$ source can affect the cheese differently, changing the amount of syneresis during salting and pressing. Cheese making procedures might need to be modified to adjust for differences between the mineral salt replacement products. Differences we noted between the 2 types of $\mathrm{KCl}$, were that $\mathrm{KCl} 1$ had a larger average particle size than $\mathrm{KCl} 2$ (386 vs. $253 \mu \mathrm{m}$ ) and a smaller distribution range (10-90\% percentile range, 259-529 vs. $30-409 \mu \mathrm{m})$. Both salts also had very different $\mathrm{pH}$ values when hydrated in water. The $\mathrm{pH}$ of a $5 \%$ solution of $\mathrm{KCl} 1$ was 7.80 , whereas that of $\mathrm{KCl} 2$ was 3.30 . The $\mathrm{pH}$ of a $5 \%$ solution of the $\mathrm{NaCl}$ used for cheese making was 6.22 . The ingredients also have different additives, with $\mathrm{KCl} 1$ containing tricalcium phosphate tribasic, and $\mathrm{KCl} 2$ containing rice flour. The effect of a lower $\mathrm{pH}$ and smaller particle size $(\mathrm{KCl} 2)$ could sug- 


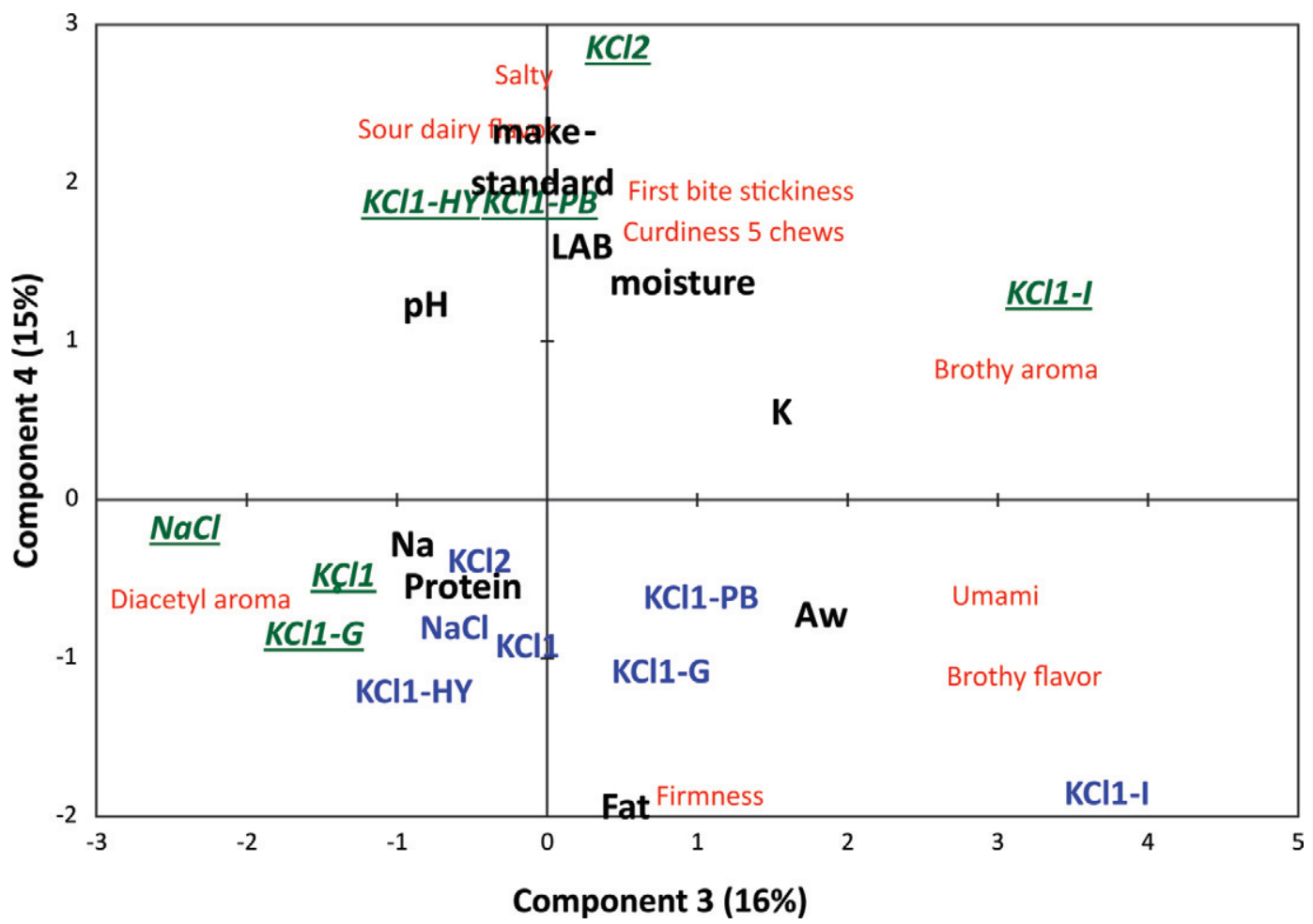

Figure 5. Plot of principal components 3 and 4 showing the position of the sensory attributes with loadings on these components greater than 0.6 and the position of instrumental measurements with correlations greater than 0.3. We input the mean sensory attribute ratings from mo 4 for all 7 cheeses and both makes (a total of 14 observations) and the 19 sensory attributes that differed significantly among these cheeses at mo 4. The 10 instrumental measurements were added as quantitative supplementary variables; make procedure was added as a supplementary qualitative variable. Cheese names in roman font (blue) are alternate make (target salting titratable acidity of $0.25 \%$ ); cheese names in underlined italic font (green) are standard make (target salting titratable acidity of $0.21 \%$ ). Sensory attributes are in gray (red); instrumental measures are in bold (black). $\mathrm{NaCl}=640 \mathrm{mg}$ of sodium $/ 100 \mathrm{~g}$ of cheese target; KCl1 = sodium chloride + KCl1 (Premier Potassium Chloride 8799, Cargill Inc., Minneapolis, MN; $220 \mathrm{mg}$ of sodium/100 g); KCl2 = sodium chloride + KCl2 (Modified Potassium Chloride 14510, Nu-Tek Products Inc., Minnetonka, MN; $220 \mathrm{mg}$ of sodium/100 g); HY = hydrolyzed vegetable protein/yeast extract blend (Savor Notes Savory Natural Flavor Enhancer 0188404, Innova, Lombard, IL); PB = DM Choice Natural Flavor "Potassium Blocker Type" 33150 Powder (David Michael \& Co., Philadelphia, PA); I = disodium 5' inosinate (AJITIDE IMP, Ajinomoto Food Ingredients LLC, Chicago, IL); G = disodium 5' guanylate (CJTIDE, PT CJ, Jakarta, Indonesia); LAB = lactic acid bacteria; Aw = water activity. Color version available in the online PDF.

gest that the salt would solubilize more quickly and drive off more moisture at salting, as lower $\mathrm{pH}$ is associated with curd shrinkage and increased syneresis (Grundelius et al, 2000). However, studies investigating the effect of $\mathrm{pH}$ on curd syneresis have been carried out at $\mathrm{pH}$ values ranging from 6.0 to 6.4 (Grundelius et al., 2000; Thomann et al., 2008), so it is possible that the $\mathrm{pH}$ of curd treated with $\mathrm{KCl} 2$ affected the surface of the curd granule and resulted in reduced syneresis. Another possibility could be other minerals present in the ingredient affected protein solubility (however, the $\mathrm{KCl}$ ingredients themselves were not tested).

Lower $\mathrm{pH}$ in cheese with added $\mathrm{KCl}$ has been observed by some researchers (Koenig and Marth, 1982; Reddy and Marth, 1995), but not by others (Fitzgerald and Buckley, 1985). The $\mathrm{pH}$ differences observed among studies could be due to the researchers having used different amounts of $\mathrm{KCl}$ to replace the $\mathrm{NaCl}$ or not having added $\mathrm{KCl}$ on a molar basis to the $\mathrm{NaCl}$ being removed. The $\mathrm{pH}$ of our cheese containing $\mathrm{KCl} 2$ tended to be lower than cheeses with KCl1 (made by the same make procedure; Figure 2). This could be due to the previously mentioned difference in the $\mathrm{pH}$ of the $\mathrm{KCl}$ ingredients, the higher moisture content in the standard make version, the lower effective salt to moisture ratio, or less inhibition of starter culture fermentation activity. The full-sodium control by the standard make had a higher $\mathrm{pH}$ than all other treatments. One obvious reason for the full-sodium standard make having a higher $\mathrm{pH}$ than the alternate is that the final target TA of the alternate make was lower, as designed, to drive off moisture. The standard make also had more added $\mathrm{NaCl}$ - again, because the moisture of the alternate was designed to be lower - so less $\mathrm{NaCl}$ could be added to achieve the same $\mathrm{NaCl}$ concentration in the final cheese, assuming the losses to the whey were the same. The result of not having less moisture in the alternate make was that the effective salt to moisture ratio tended to 


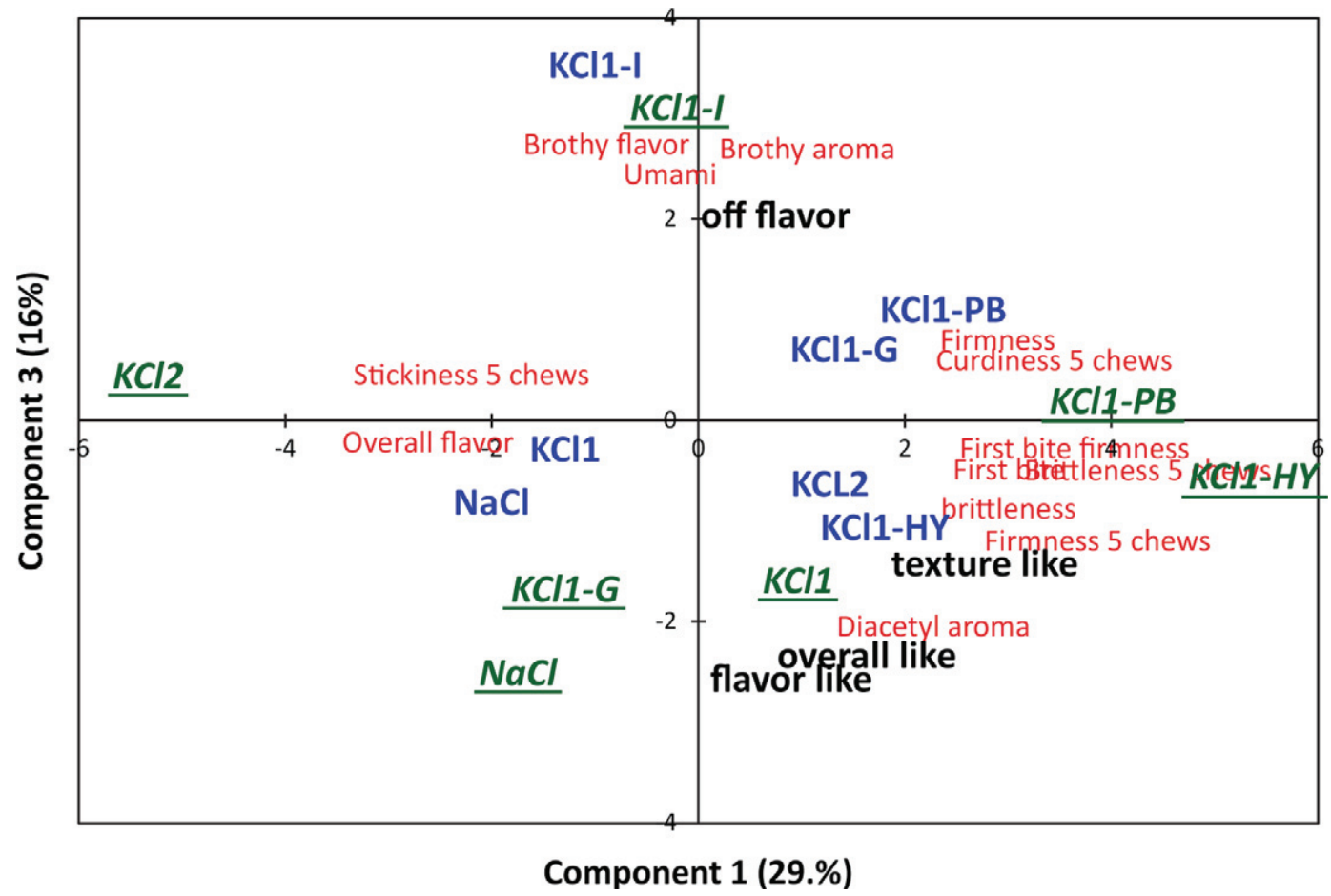

Figure 6. Plot of principal components 1 and 3 showing the position of the sensory attributes with loadings on these components greater than 0.6 and the position of consumer liking ratings. We input the mean sensory attribute ratings from mo 4 for all 7 cheeses and both makes (a total of 14 observations) and the 19 sensory attributes that differed significantly among these cheeses at mo 4 . The 4 consumer liking means were added as quantitative supplementary variables; make procedure was added as a supplementary qualitative variable. Cheese names in roman font (blue) are alternate make (target salting titratable acidity of $0.25 \%$ ); cheese names in underlined italic font (green) are standard make (target salting titratable acidity of $0.21 \%$ ). Sensory attributes are in gray (red); instrumental measures are in bold (black). NaCl $=640 \mathrm{mg}$ of sodium/100 g of cheese target; KCl1 = sodium chloride + KCl1 (Premier Potassium Chloride 8799, Cargill Inc., Minneapolis, MN; 220 mg of sodium/100 g); KCl2 = sodium chloride + KCl2 (Modified Potassium Chloride 14510, Nu-Tek Products Inc., Minnetonka, MN; 220 mg of so$\operatorname{dium} / 100 \mathrm{~g}) ; \mathrm{HY}=$ hydrolyzed vegetable protein/yeast extract blend (Savor Notes Savory Natural Flavor Enhancer 0188404, Innova, Lombard, IL); PB = DM Choice Natural Flavor "Potassium Blocker Type" 33150 Powder (David Michael \& Co., Philadelphia, PA); I = disodium 5' inosinate (AJITIDE IMP, Ajinomoto Food Ingredients LLC, Chicago, IL); G = disodium 5' guanylate (CJTIDE, PT CJ, Jakarta, Indonesia). Color version available in the online PDF.

be higher in the standard make than the alternate, and better control over bacterial and enzymatic activity should have been achieved in the standard make procedure cheeses, resulting in better cheese (Table 5). When calculated as the percentage loss of $\mathrm{NaCl}$ added to the curd, the full-sodium standard and alternate makes had a 24 and $30 \%$ loss, respectively. This was calculated based on the total sodium in the cheese and does not take into account sodium naturally present. Both $\mathrm{NaCl}$ losses are in the typical range of that reported for Cheddar cheese making. The full-sodium cheese made with the alternate make procedure, with its higher TA target, had a lower ash and sodium concentration than full-sodium cheese made by the standard make procedure (Table 5). But no differences were recorded in ash or sodium based on make procedure for the reduced sodium cheeses. The loss of $\mathrm{NaCl}$ in Cheddar usually varies with the salting rate, with approximately 10 to $15 \%$ of added salt lost at very low salting rates $(0.5 \%$; Fox et al., 2000) and up to $50 \%$ loss at higher salting rates (2.7\%; Sutherland, 1974; Nair et al., 2004). For our reduced sodium treatments that were salted at $0.7 \%$ of the weight of the curd, we lost between 13 and $26 \%$ $\mathrm{NaCl}$. No pattern to differences in losses was noted, however, the standard make procedure with $\mathrm{KCl1}$ and $\mathrm{KCl} 2$ had 23 and $13 \%$ losses, and the alternate make procedure with $\mathrm{KCl} 1$ and $\mathrm{KCl} 2$ had 20 and $26 \%$ loss, respectively. The low loss of $\mathrm{NaCl}$ in the standard make $\mathrm{KCl} 2$ treatment makes sense in that this treatment had the highest moisture and, therefore, the least moisture syneresis from the curd and lowest concomitant $\mathrm{NaCl}$ loss to the whey.

All of the cheeses showed an increase in WSN over time, as expected (Figure 3). Other studies at various levels of $\mathrm{KCl}$ addition found no difference in proteolysis between reduced sodium cheeses with and without $\mathrm{KCl}$ (Aly, 1995; Reddy and Marth, 1995; Laborda and Rubiolo, 1999; Katsiari et al., 2001; Ayyash and Shah, 2011). However, Fitzgerald and Buckley (1985) reported varied effects of $\mathrm{KCl}$. They observed an average decrease 


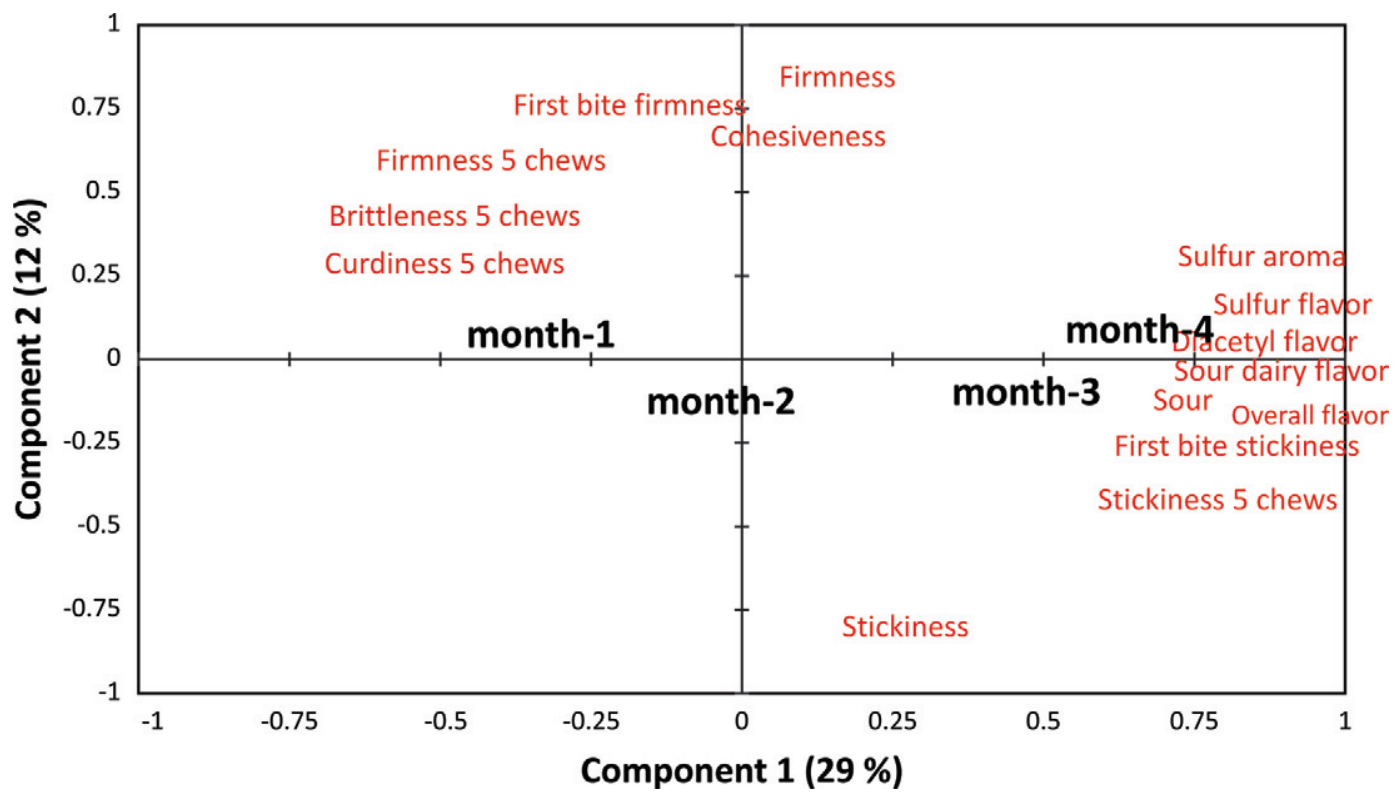

Figure 7. Plot of principal components 1 and 2 showing the position of the sensory attributes with loadings on these components greater than 0.6 and the position of the centroids for the aging time (mo). We input the mean sensory attribute ratings from mo 1 to 4 for all 7 cheeses and both makes (a total of 56 observations), and the 29 sensory attributes that differed significantly among these cheeses, times, and makes. The 4 mo were added as quantitative supplementary variables; make procedure was added as a supplementary qualitative variable. Color version available in the online PDF.

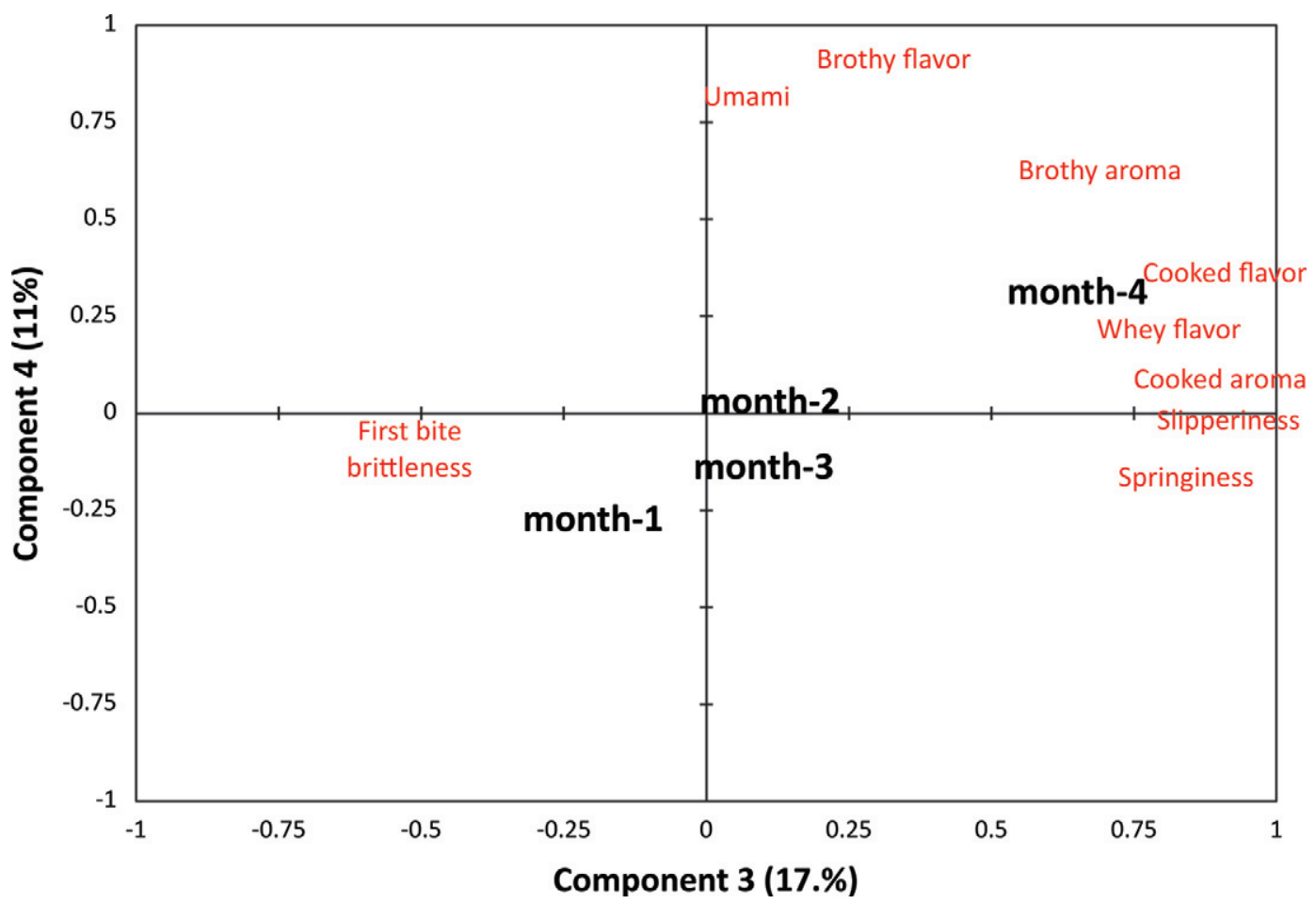

Figure 8. Plot of principal components 3 and 4 showing the position of the sensory attributes with loadings on these components greater than 0.6 and the position of the centroids for the aging time (mo). We input the mean sensory attribute ratings from mo 1 to 4 for all 7 cheeses and both makes (a total of 56 observations) and the 29 sensory attributes that differed significantly among these cheeses, times, and makes. The 4 mo were added as quantitative supplementary variables; make procedure was added as a supplementary qualitative variable. Color version available in the online PDF. 
Table 6. Mean consumer acceptability scores of 5-mo-old Cheddar cheese ${ }^{1}$

\begin{tabular}{|c|c|c|c|c|c|}
\hline \multirow[b]{2}{*}{ Procedure $^{2}$} & \multirow[b]{2}{*}{ Treatment $^{3}$} & \multicolumn{4}{|c|}{ Attribute } \\
\hline & & $\begin{array}{l}\text { Overall } \\
\text { liking }\end{array}$ & $\begin{array}{l}\text { Flavor } \\
\text { liking }\end{array}$ & $\begin{array}{l}\text { Texture } \\
\text { liking }\end{array}$ & Off-flavor \\
\hline Standard & $\begin{array}{l}\mathrm{NaCl} \\
\mathrm{KCl} 1 \\
\mathrm{KCl} 2 \\
\mathrm{KCl} 1+\mathrm{G} \\
\mathrm{KCl} 1+\mathrm{HY} \\
\mathrm{KCl} 1+\mathrm{I} \\
\mathrm{KCl} 1+\mathrm{PB}\end{array}$ & $\begin{array}{l}74^{\mathrm{a}} \\
69^{\mathrm{abc}} \\
68^{\mathrm{abc}} \\
67^{\mathrm{abc}} \\
67^{\mathrm{abc}} \\
56^{\mathrm{d}} \\
72^{\mathrm{ab}}\end{array}$ & $\begin{array}{l}74^{\mathrm{a}} \\
68^{\mathrm{ab}} \\
66^{\mathrm{abc}} \\
66^{\mathrm{abc}} \\
65^{\mathrm{bc}} \\
52^{\mathrm{d}} \\
70^{\mathrm{ab}}\end{array}$ & $\begin{array}{l}72^{\mathrm{a}} \\
72^{\mathrm{ab}} \\
69^{\mathrm{ab}} \\
72^{\mathrm{ab}} \\
72^{\mathrm{ab}} \\
67^{\mathrm{b}} \\
74^{\mathrm{a}}\end{array}$ & $\begin{array}{l}4^{\mathrm{d}} \\
6^{\mathrm{cd}} \\
5^{\mathrm{cd}} \\
6^{\mathrm{bc}} \\
5^{\mathrm{cd}} \\
9^{\mathrm{a}} \\
4^{\mathrm{d}}\end{array}$ \\
\hline Alternate & $\begin{array}{l}\mathrm{NaCl} \\
\mathrm{KCl} 1 \\
\mathrm{KCl} 2 \\
\mathrm{KCl} 1+\mathrm{G} \\
\mathrm{KCl} 1+\mathrm{HY} \\
\mathrm{KCl} 1+\mathrm{I} \\
\mathrm{KCl} 1+\mathrm{PB}\end{array}$ & $\begin{array}{l}66^{\mathrm{bc}} \\
69^{\mathrm{abc}} \\
69^{\mathrm{abc}} \\
69^{\mathrm{abc}} \\
72^{\mathrm{ab}} \\
62^{\mathrm{c}} \\
73^{\mathrm{ab}}\end{array}$ & $\begin{array}{l}65^{\mathrm{bc}} \\
67^{\mathrm{abc}} \\
67^{\mathrm{abc}} \\
67^{\mathrm{abc}} \\
71^{\mathrm{ab}} \\
60^{\mathrm{c}} \\
71^{\mathrm{ab}}\end{array}$ & $\begin{array}{l}73^{\mathrm{ab}} \\
74^{\mathrm{a}} \\
74^{\mathrm{a}} \\
74^{\mathrm{a}} \\
74^{\mathrm{a}} \\
71^{\mathrm{ab}} \\
73^{\mathrm{a}}\end{array}$ & $\begin{array}{l}6^{\mathrm{cd}} \\
6^{\mathrm{bcd}} \\
5^{\mathrm{cd}} \\
5^{\mathrm{cd}} \\
5^{\mathrm{cd}} \\
7^{\mathrm{b}} \\
5^{\mathrm{cd}}\end{array}$ \\
\hline $\begin{array}{l}\mathrm{SE}^{4} \\
P \text {-value }\end{array}$ & & $\begin{array}{c}2.6 \\
<0.001\end{array}$ & $\begin{array}{c}2.7 \\
<0.001\end{array}$ & $\begin{array}{c}2.1 \\
<0.001\end{array}$ & $\begin{array}{c}0.6 \\
<0.001\end{array}$ \\
\hline
\end{tabular}

${ }^{\mathrm{a}-\mathrm{d}}$ Means without a common superscript letter within the same column are significantly different $(P<0.05)$.

${ }^{1}$ Liking ratings were made by 117 panelists on 120-point labeled affective magnitude scales, with the left end labeled "greatest imaginable disliking" and the right end labeled "greatest imaginable liking." Panelists were instructed to take a second bite of the sample and rate the intensity of any off-flavor. This rating was made on a 20-point line scale with the left end labeled "none" $(=1)$ and the right end labeled "extremely intense" $(=20)$. ${ }^{2}$ Standard $=$ standard make procedure with a $0.21 \%$ target titratable acidity at salting; Alternate = alternate make procedure with a target titratable acidity of $0.25 \%$ at salting and smaller curd knives were used during cheese making (6.4 vs. $9.5 \mathrm{~mm}$ ).

${ }^{3} \mathrm{NaCl}=$ full sodium control $(640 \mathrm{mg}$ of sodium $/ 100 \mathrm{~g}$ of cheese target $) ; \mathrm{KCl} 1=$ sodium chloride $+\mathrm{KCl1}$ (Premier Potassium Chloride 8799, Cargill Inc., Minneapolis, MN; $220 \mathrm{mg}$ of sodium/100 g of cheese target); $\mathrm{HY}=$ hydrolyzed vegetable protein/yeast extract blend; $\mathrm{PB}=$ natural potassium blocker type flavor; $\mathrm{I}=$ disodium 5 ' inosinate; $\mathrm{G}=$ disodium guanylate; $\mathrm{KCl} 2=$ sodium chloride $+\mathrm{KCl} 2$ (Modified Potassium Chloride 14510, Nu-Tek Products Inc., Minnetonka, MN; $220 \mathrm{mg}$ of sodium/100 g of target).

${ }^{4}$ Largest standard error for each attribute is shown.

in water soluble nitrogen of $2.9 \%$ when only $\mathrm{KCl}$ was used, and an increase of $1.3 \%$ over 16 wk when $\mathrm{NaCl} /$ $\mathrm{KCl}$ (1:1 weight ratio) was used. It was interesting, in our study, that the $\mathrm{KCl}$ source affected the percentage WSN (possibly because KCl2-containing cheeses had a higher moisture, in general; Table 4; Figures 1 and 4). The alternate make procedure was also higher in WSN than the standard (Table 4); this could be attributed to the generally lower effective salt to moisture ratio that occurred with this procedure, with the exception of the KCl1 treatment (Table 5).

We observed no differences in LAB between treatments, similar to results reported by Reddy and Marth (1995; Table 4). They observed no difference between LAB counts of Cheddar cheese treatments salted with various $\mathrm{NaCl} / \mathrm{KCl}$ mixtures through 36 wh of aging, despite a slightly lower $\mathrm{pH}$ in cheeses with $\mathrm{KCl}$ at $3 \mathrm{~d}$ of age. In our study, the counts of LAB declined approximately $1 \log$ over the 4 mo monitored (data not shown).

With the differences in WSN and $\mathrm{pH}$ observed with $\mathrm{KCl}$ source and make procedure, some differences in the sensory and texture properties would be expected. In regards to the make procedure, the greatest difference between the makes was that the alternate make had a higher brothy flavor than the standard make (Figure 5). The least firm treatment overall was the standard make with $\mathrm{KCl} 2$. That treatment had the highest moisture of all treatments, the highest WSN, and was also the most sticky (Figure 4). Bitterness is a common complaint with the use of $\mathrm{KCl}$, as observed in cheese in various sodium reduction studies (Lindsay et al., 1982; Aly, 1995; Katsiari et al., 1997). In this study, bitterness scores were higher for cheeses with $\mathrm{KCl}$ than full-sodium control (Figure 4), but the descriptive scores were very low, all being $<1.8$.

The sensory attributes of low sodium treatments with KCl1 and flavor enhancers (hydrolyzed vegetable protein, potassium blocker, disodium $5^{\prime}$ inosinate, and disodium $5^{\prime}$ guanylate) were not different than the low sodium treatments without the flavor enhancers with the following exception: the treatment with disodium $5^{\prime}$ inosinate resulted in higher umami and brothy flavor intensities (Figure 6) that appear to have reduced 
consumer acceptability (Figure 6; Table 6). Shakeel-UrRehman et al. (2003) added a self-manufactured, dried yeast extract to reduced fat Cheddar cheese and found it to have higher sulfur, nutty, sweet, and fruity flavors at 7 mo of ripening, where the control was higher in brothy and umami flavors. They also found an increase in the initial counts of nonstarter lactic acid bacteria and attributed this activity to the development of flavor compounds from the amino acids generated by this culture activity. We did not measure the nonstarter lactic acid bacteria directly, so it is unknown if the addition of hydrolyzed vegetable protein, disodium $5^{\prime}$ inosinate, and disodium $5^{\prime}$ guanylate, sources of amino acids, affected their growth or metabolism. The enhancers were added to the cheese at levels where a desirable sensory effect was observed during our screening procedure, with an overuse based on our expected loss during salting (Tables 2 and 3). The lack of differences observed with hydrolyzed vegetable protein and disodium $5^{\prime}$ guanylate could be due to greater losses during salting, or to changes that occurred during ripening (such as metabolism by microorganisms). Inosinate was apparently either sufficiently retained and not metabolized, or stimulated bacteria during ripening to produce the brothy and umami flavors observed by the trained panel and disliked by consumers. Consumers also scored the disodium $5^{\prime}$ inosinate samples as having a higher off-flavor than the other treatments (Table 6). Both potassium blocker and hydrolyzed vegetable protein seemed to have improved the flavor of the alternate make cheese, as they had the highest overall liking and flavor liking scores within that make procedure (Table 6 ). Interestingly, the PB treatment was scored lowest for off-flavor among the cheeses with added $\mathrm{KCl}$ by both make procedures (Table 6). Generally, the flavor enhancers affected the consumer acceptance scores only slightly. Although most of these effects were not statistically significant, excluding those from treatments containing I (disodium $5^{\prime}$ inosinate), they do suggest the possibility of altering the consumer acceptance of low sodium cheese through the use of flavor enhancers.

\section{CONCLUSIONS}

This study demonstrated that low sodium Cheddarstyle cheese with $\mathrm{KCl}$ can be made in a way that results in high consumer acceptance, low bitterness, and an equivalent saltiness to control when the $\mathrm{KCl}$ is used at levels to maintain the $\mathrm{a}_{\mathrm{w}}$, resulting in an equivalent effective salt to moisture ratio. The addition of flavor enhancers to Cheddar curd had mixed results. Some seemed to have modified the flavor in a positive way in the judgment of consumers in a sensory panel, whereas another resulted in a significant reduction in liking scores. Brothy flavor and aroma and umami flavor were increased in cheese containing disodium $5^{\prime}$ inosinate as judged by the descriptive panel, and those attributes lead to lower ratings in the consumer panel. Potassium chloride replacement salts from different manufacturers can also have an effect on the chemical and flavor properties of cheese, and changes to cheese-making procedures and targets may be necessary to yield cheese with the desired final moisture and $\mathrm{pH}$.

\section{ACKNOWLEDGMENTS}

Funding was provided by Dairy Research Institute, managed by Dairy Management Inc. (Rosemont, IL). We thank the funder and companies who supplied salt replacer and flavor enhancing ingredients. The use of trade names in this publication does not imply endorsement by the funding organization, the University of Minnesota, or the researchers, nor does it imply criticism of materials we did not evaluate.

\section{REFERENCES}

Agarwal, S., D. McCoy, D. McCoy, W. Graves, P. D. Gerard, and S. Clark. 2011. Sodium content in retail Cheddar, Mozzarella, and process cheeses varies considerably in the United States. J. Dairy Sci. 94:1605-1615.

Aly, M. E. 1995. An attempt for producing low-sodium feta-type cheese. Food Chem. 52:295-299.

Appel, L. J., S. Y. Angell, L. K. Cobb, H. M. Limper, D. E. Nelson, J. M. Samet, and R. C. Brownson. 2012. Population-wide sodium reduction: The bumpy road from evidence to policy. Ann. Epidemiol. 22:417-425.

ASTM. 2010. ASTM Standard E544-10: Standard practice for suprathreshold intensity measurement. American Society for Testing and Materials, Philadelphia, PA.

Ayyash, M. M., and N. P. Shah. 2011. Effect of partial substitution of $\mathrm{NaCl}$ with $\mathrm{KCl}$ on proteolysis of halloumi cheese. J. Food Sci. 76:C31-C37.

Brandsma, I. 2006. Reducing sodium: A European perspective. Food Technol. 60:24-29.

Cotugna, N., and S. Wolpert. 2011. Sodium recommendations for special populations and the resulting implications. J. Community Health 36:874-882.

Doyle, M. E., and K. A. Glass. 2010. Sodium reduction and its effect on food safety, food quality, and human health. Compr. Rev. Food Sci. Food Safety 9:44-56.

Drake, S. L., M. E. Carunchia Whetstine, M. A. Drake, P. Courtney, K. Fligner, J. Jenkins, and C. Pruitt. 2007. Sources of umami taste in Cheddar and Swiss cheeses. J. Food Sci. 72:S360-S366.

FDA. 2009. Guidance for Industry: A food labeling guide, Appendix F: Calculate the percent daily value (DV) for the appropriate nutrients. Accessed Dec. 12, 2012. www.fda.gov/FoodLabelingGuide.

Fitzgerald, E., and J. Buckley. 1985. Effect of total and partial substitution of sodium-chloride on the quality of Cheddar cheese. J. Dairy Sci. 68:3127-3134.

Fox, P. F., T. P. Guinee, T. M. Cogan, and P. L. H. McSweeney. 2000. Salting of cheese curd. Pages 153-168 in Fundamentals of Cheese Science. Aspen Publishers Inc., Gaithersburg, MD.

Grummer, J., M. Karalus, K. Zhang, Z. Vickers, and T. C. Schoenfuss. 2012. Manufacture of reduced-sodium Cheddar-style cheese with mineral salts. J. Dairy Sci. 95:2830-2839.

Grummer, J., and T. Schoenfuss. 2011. Determining salt concentrations for equivalent water activity in reduced-sodium cheese by use of a model system. J. Dairy Sci. 94:4360-4365. 
Grundelius, A. U., K. Lodaite, K. Ostergren, M. Paulsson, and P. Dejmek. 2000. Syneresis of submerged single curd grains and curd rheology. Int. Dairy J. 10:489-496.

Guinee, T. P. 2004. Salting and the role of salt in cheese. Int. J. Dairy Technol. 57:99-109.

Henney, J. E., C. L. Taylor, and C. S. Boon. 2010. Strategies to Reduce Sodium Intake in the United States. National Academies Press, Washington, DC.

ISO-IDF. 2007. Milk and Milk Products-Determination of calcium, sodium, potassium, calcium and magnesium contents-Atomic absorption spectrometric method. International Standard ISO 8070:2007/IDF 119:2007. International Dairy Federation (IDF), Brussels, Belgium, and International Organization for Standardization (ISO), Geneva, Switzerland.

Katsiari, M. C., E. Alichanidis, L. P. Voutsinas, and I. G. Roussis. 2001. Proteolysis in reduced sodium Kefalograviera cheese made by partial replacement of $\mathrm{NaCl}$ with $\mathrm{KCl}$. Food Chem. 73:31-43.

Katsiari, M. C., L. P. Voutsinas, E. Alichanidis, and I. G. Roussis 1997. Reduction of sodium content in feta cheese by partial substitution of $\mathrm{NaCl}$ by $\mathrm{KCl}$. Int. Dairy J. 7:465-472.

Katsiari, M. C., L. P. Voutsinas, E. Alichanidis, and I. G. Roussis 1998. Manufacture of Kefalograviera cheese with less sodium by partial replacement of $\mathrm{NaCl}$ with $\mathrm{KCl}$. Food Chem. 61:63-70.

Kira, C. S., F. D. Maio, and V. A. Maihara. 2004. Comparison of partial digestion procedures for determination of $\mathrm{Ca}, \mathrm{Cr}, \mathrm{Cu}, \mathrm{Ce}$, $\mathrm{K}, \mathrm{Cg}, \mathrm{Mn}, \mathrm{Na}, \mathrm{P}$, and $\mathrm{Zn}$ in milk by inductively coupled plasmaoptical emission spectrometry. J. AOAC Int. 87:151-156.

Koenig, S., and E. H. Marth. 1982. Behavior of Staphylococcus aureus in Cheddar cheese made with sodium-chloride or a mixture of sodium-chloride and KCl. J. Food Prot. 45:996-1002.

Kosikowski, F. V. 1983. Low sodium cheddar cheeses through whole milk retentate supplementation. J. Dairy Sci. 66:2494-2500.

Kuchroo, C. N., and P. F. Fox. 1982. Soluble nitrogen in Cheddar cheese - Comparison of extraction procedures. Milchwissenschaft $37: 331-335$.

Laborda, M. A., and A. C. Rubiolo. 1999. Proteolysis of Fynbo cheese salted with $\mathrm{NaCl} / \mathrm{KCl}$ and ripened at two temperatures. J. Food Sci. 64:33-36.

Lindsay, R. C., S. M. Hargett, and C. S. Bush. 1982. Effect of sodiumpotassium $(1-1)$ chloride and low sodium-chloride concentrations on quality of Cheddar cheese. J. Dairy Sci. 65:360-370.
Nair, S. S., V. V. Mistry, and K. R. Nauth. 2004. Reduction of salt $(\mathrm{NaCl})$ losses during the manufacture of Cheddar cheese. J. Dairy Sci. $87: 2831-2838$

Reddy, K. A., and E. H. Marth. 1991. Reducing the sodium content of foods-A review. J. Food Prot. 54:138-150.

Reddy, K. A., and E. H. Marth. 1995. Microflora of Cheddar cheese made with sodium-chloride, potassium-chloride, or mixtures of sodium and potassium-chloride. J. Food Prot. 58:54-61.

Richardson, G. H. 1985. Standard Methods for the Examination of Dairy Products. 15th ed. American Public Health Association, Washington, DC

Schroeder, C. L., F. W. Bodyfelt, C. J. Wyatt, and M. R. McDaniel. 1988. Reduction of sodium chloride in Cheddar cheese: Effect on sensory, microbiological, and chemical properties. J. Dairy Sci. 71:2010-2020.

Shakeel-Ur-Rehman, N. Y. Farkye, E. R. Vedamuthu, and M. A. Drake. 2003. A preliminary study on the effect of adding yeast extract to cheese curd on proteolysis and flavour development of reduced-fat Cheddar. J. Dairy Res. 70:99-103.

Sutherland, B. J. 1974. Control of salt absorption and whey drainage in Cheddar cheese manufacture. Aust. J. Dairy Technol. 29:86-93.

Thomann, S., P. Schenkel, and J. Hinrichs. 2008. Effect of homogenization, microfiltration and $\mathrm{pH}$ on curd firmness and syneresis of curd grains. Lebenson. Wiss. Technol. 5:826-835.

Upreti, P., and L. E. Metzger. 2007. Influence of calcium and phosphorus, lactose, and salt-to-moisture ratio on Cheddar cheese quality: PH changes during ripening. J. Dairy Sci. 90:1-12.

USDA. 2011. USDA National Nutrient Database for Standard Reference. USDA Agricultural Research Service Nutrient Data Laboratory. Accessed Jan. 28, 2011. http://www.nal.usda.gov/fnic/ foodcomp/search/.

Wehr, H. M., and J. F. Frank. 2004. Standard Methods for the Examination of Dairy Products. 17th ed. American Public Health Association, Washington, DC.

Young, N. D., M. Drake, K. Lopetcharat, and M. R. McDaniel. 2004. Preference mapping of Cheddar cheese with varying maturity levels. J. Dairy Sci. 87:11-19. 